\title{
The Immune-Enhancing Properties of Hwanglyeonhaedok-Tang-Mediated Biosynthesized Gold Nanoparticles in Macrophages and Splenocytes
}

\author{
Xiao-Jie $\mathrm{Mi}^{1}$ \\ Xing Yue $\mathrm{Xu}^{\prime}$ \\ Han Sol Choi \\ Hoon Kim' \\ Ik Hyun Cho ${ }^{2}$ \\ Tae-Hoo Yi (iD ${ }^{\prime}$ \\ Yeon-Ju Kim' \\ 'Graduate School of Biotechnology, and \\ College of Life Science, Kyung Hee \\ University, Yongin-si, 17I04, Gyeonggi- \\ do, Republic of Korea; ${ }^{2}$ Department of \\ Science in Korean Medicine and Brain \\ Korea 2 I Plus Program, Graduate School, \\ Kyung Hee University, Seoul, 02447, \\ Republic of Korea
}

Correspondence: Yeon-Ju Kim; lk Hyun Cho Tel +82-3I-20I-5634

Fax+82-31-204-8II6

Email yeonjukim@khu.ac.kr;

ihcho@khu.ac.kr
Background: Despite great advances in the field of immunotherapy, there is still a need for novel and effective immunostimulants to overcome challenges, such as instability and autoinflammatory toxicity, associated with conventional immunostimulants. Nanotechnology provides the possibility to overcome these challenges. The well-known classical Chinese formula, Hwanglyeonhaedok-tang (HHT) has been widely used to treat immune-related diseases in clinical practice.

Methods: We developed novel gold nanoparticles (AuNPs) utilizing one-pot synthesis with the herbal formula-HHT. The optimal conditions for HHT-AuNP biosynthesis were established, and physicochemical properties of the optimized HHT-AuNPs were identified using various spectrometric and microscopic techniques. Bio-TEM analysis revealed that HHTAuNPs were highly engulfed within RAW264.7 cells without inducing cytotoxicity. The effect of HHT-AuNPs on immunostimulatory activity was evaluated in innate and adaptive immune cells (RAW264.7 macrophages and ICR mice splenocytes) using qRT-PCR, immunoblotting, and ELISA.

Results: The HHT-AuNPs remarkably increased the nitric oxide (NO) and immune-related cytokines production by activating the mitogen-activated protein kinase (MAPK) and nuclear factor- $\kappa \mathrm{B}(\mathrm{NF}-\kappa \mathrm{B})$ signaling pathways in RAW264.7 cells. Furthermore, HHT-AuNPs exerted immunostimulatory effects on mouse splenocytes by priming $\mathrm{T} / \mathrm{B}$-cells and macrophages.

Discussion: The present study is the first to demonstrate that HHT-AuNPs could be utilized as immunostimulators to activate both innate and adaptive immune systems. These results provide a foundation for the application of traditional Chinese medicinal formulae in the field of nanomedicine.

Keywords: HHT, herb formula, green synthesis, AuNPs, immunostimulation

\section{Introduction}

The immune response is an essential biological process that protects the body from various invading pathogens, intracellular danger signals, and tumorigenesis. ${ }^{1}$ An ideal immunostimulant can improve host defense against pathogens by regulating the activation of immune cells. ${ }^{2}$ Furthermore, immune activation has been a long-term goal for treating immunosuppressive diseases and preventing infectious diseases. ${ }^{3,4}$ Conventional immunostimulants potentiate antitumor immune responses and induces 
tumor regression; however, this often results in adverse inflammatory events. ${ }^{5}$ Recombinant human interferon alfa (IFN- $\alpha$ ) and the cytokine interleukin-2 (IL-2) were approved for the adjuvant immunotherapy of patients with resected high-risk melanoma in 1992 and 1998, respectively. Nonetheless, the enthusiasm for using these immunostimulants has been tempered by the frequent and severe adverse events induced by their use. The constitutional symptoms, including fever, swelling, fatigue, headache, and myalgias, have been reported in more than $80 \%$ of patients. Such side effects need to be controlled using anti-inflammatory drugs, whereas severe symptoms often require a treatment hiatus. ${ }^{6}$ Such challenges have not been adequately addressed by classical adjuvants. ${ }^{5}$ Growing evidence suggests that nanotechnology may meet the needs of current immunotherapies and that nanotechnology-based immunostimulants may be the preferential option. ${ }^{7}$

Over the past decade, biomaterial-based nanoparticles have enabled advances in innovative translational research to develop biomedicines. ${ }^{8,9}$ The immune-stimulating properties of these nanocarriers were intensively investigated as a new prophylactic and therapeutic approach to initiate and modulate immune responses. ${ }^{5}$ Although nanoparticles have been widely developed, their toxicity to normal cells remains one of the main challenges that limit their therapeutic application. ${ }^{10}$ Gold nanoparticles (AuNPs) receive the most attention as they usually exhibit relatively low toxicity owing to their inert and non-toxic core. ${ }^{11}$ However, the conventional chemical synthesis of nanoparticles involves toxic chemicals and requires high energy for production. ${ }^{12}$ Biogenic routes, especially the plantbased synthesis of AuNPs, have been the preferred production strategy, as it avoids the use of toxic materials. ${ }^{11}$ Various polyphenols and hydroxyl groups in plant sources can synthesize AuNPs from gold salt via a reduction reaction. ${ }^{13,14}$ Furthermore, plant-mediated AuNPs exhibit enhanced stability and stronger bioactivity than those of plant extracts. ${ }^{15}$ Therefore, plant sources provide a promising solution for the synthesis and application of AuNPs.

Plant adjuvants, such as those derived from Quillaja saponaria, ${ }^{16}$ Asparagus racemosus, ${ }^{17}$ and Tamarindus indica extracts, can be used as immunostimulants in combination with AuNPs. ${ }^{18}$ Accordingly, the use of plant sources to biosynthesize AuNPs to enhance their immunostimulatory activity has been explored too. Elbagory et al reported the in vitro immunomodulatory effects of AuNPs synthesized from Hypoxis hemerocallidea extract. ${ }^{19}$ However, their study based on the combined administration of AuNPs and lipopolysaccharides (LPS) did not reveal the mechanism underlying stimulation of immune cells using herb extract-mediated AuNPs.

Furthermore, the limitations of bioactivity and toxicity from single herbal extracts appear to have been overlooked in recent studies on AuNPs developed with herbal extracts. As early as 2500 years ago, combination therapy of several herbs was advocated and called "formulae" in traditional Chinese medicine (TCM). ${ }^{20}$ Much ancient literature suggests that herbal mixtures exhibit considerably more curative effects than a single herbal. ${ }^{21}$ Moreover, multiple components of some formulae can act on several targets and exert synergistic therapeutic efficacy. ${ }^{22}$ A combination therapy using herbal formula has received much interest as the most popular approach in TCM. The utilization of herbal formulae for nanofabrication has not yet been extensively studied. Among the famous TCM formulae, Hwanglyeonhaedok-tang (HHT), a well-known classical Chinese prescription described in "Wai Tai Mi Yao", is officially listed in the Chinese Pharmacopeia and widely used for the treatment of immune-related diseases in clinical practice. ${ }^{23}$ HHT exerts prominent effect in improving immune function in animal models and patients with immune dysfunction by activating various immune cell types, including macrophages and NK cells, which regulate the expression of immune-related cytokines. ${ }^{24,25}$ HHT comprises four herbal medicines: Rhizoma coptidis, Radix scutellariae, Cortex phellodendri, and Fructus gardenia. ${ }^{26}$ The active ingredients of HHT consist of total alkaloids, total flavonoids, and total iridoid. Plant flavonoids and total iridoid can act as reducing and capping agents to produce AuNPs. $^{27}$

In this study, HHT was used to biosynthesize AuNPs in an eco-friendly and economical manner considering their biological function. The optimal reaction conditions, including the HHT concentration, gold precursor concentration, reaction temperature, time, and $\mathrm{pH}$, were evaluated to achieve the large-scale bioreduction of AuNPs. The synthesized AuNPs were characterized using several physicochemical techniques, including ultraviolet-visible (UVVis) spectrophotometry, elemental mapping, selected area electron diffraction (SAED), energy-dispersive X-ray spectrometry (EDX), transmission electron microscopy (TEM), field emission scanning electron microscopy (FESEM), powder X-ray diffraction (XRD), and Fouriertransform infrared (FTIR) spectroscopy. Because of the complexity of the immune system, our goal was to 
elucidate the response of the immunological mechanism to HHT-AuNPs in macrophages and primary splenocytes of mice.

\section{Materials and Methods Materials}

RPMI 1640 culture medium, Dulbecco's modified Eagle medium (DMEM), and fetal bovine serum (FBS) were purchased from GenDEPOT (Katy, TX, USA). The antibiotics (penicillin and streptomycin) were procured from Invitrogen Corp. (Carlsbad, CA, USA). LPS, dimethyl sulfoxide (DMSO), soluble 3-(4, 5-dimethylthiazol-2-yl)2, 5-diphenyltetrazolium bromide (MTT), Hoechst 33258, and Griess reagents were obtained from Sigma-Aldrich (St. Louis, MO, USA). The LIVE/DEADTM Viability/ Cytotoxicity Kit was provided from Life Technologies (Carlsbad, CA, USA). Quanti-MaxTM WST-8 cell viability assay kit was purchased from Biomax Co., Ltd. (Seoul, Korea). Hydrogen tetrachloroaurate hydrate $\left(\mathrm{HAuCl}_{4} 3 \mathrm{H}_{2} \mathrm{O}\right.$, gold salt) was supplied by Strem Chemicals, Inc. (Newburyport, MA, USA). Enzymelinked immunosorbent assay (ELISA) kits for the detection of tumor necrosis factor-alpha (TNF- $\alpha$ ), IL-1 $\beta$, IL-6), interleukin-2 (IL-2), and interferon-gamma (IFN- $\gamma$ ) were purchased from R\&D Systems (Minneapolis, USA). The primary antibodies against $\mathrm{I} \kappa \mathrm{B} \alpha, \mathrm{p}-\mathrm{I} \kappa \mathrm{B} \alpha, \mathrm{NF}-\kappa \mathrm{B}, \mathrm{p}-\mathrm{NF}-$ $\kappa \mathrm{B}$, and $\beta$-actin were purchased from Cell Signaling Technology (Danvers, MA, USA). The primary antibodies against extracellular signal-related kinase (ERK), p-ERK, c-Jun N-terminal kinase (JNK), p-JNK, p-p38, and p38 were obtained from Proteintech (IL, USA). All other chemicals and reagents used in this analysis were of reagentgrade quality and are commercially available.

\section{Preparation of HHT Extract}

The four dried medicinal herbs constituting HHT (Rhizoma coptidis, Radix scutellariae, Cortex phelloden$d r i$, and Fructus gardenia) were purchased from Omniherb Co., Ltd. (Daegu, South Korea). Each dried herb was mixed in a ratio of $1: 1: 1: 1$ by weight (100 $\mathrm{g}$ in total) and cut into small pieces. The HHT extracts were prepared using a previously described method. ${ }^{28}$ Briefly, the herbal mixture was incubated in $1.0 \mathrm{~L}$ distilled water for $90 \mathrm{~min}$ using a reflux extraction system and subsequently boiled for $90 \mathrm{~min}$. The aqueous extract was filtered through Whatman No. 4 filter paper with a 20-25 $\mu \mathrm{m}$ pore size and concentrated by vacuum evaporation using an EYELA
N-1200A (EYELA, Rikakikai Co. Ltd., Tokyo, Japan) at $60^{\circ} \mathrm{C}$. The viscous extract was lyophilized and stored at $-80^{\circ} \mathrm{C}$ until use. The final yield was $17.6 \%$.

\section{High Performance Liquid Chromatography (HPLC)}

The marker compounds of HHT were identified by HPLC analysis using a PerkinElmer Flexar QUATERNARY Pump (Shelton, CT, USA) equipped with a PerkinElmer PDA LC Detector (Shelton, CT, USA). Chromatographic separation was performed on an INNO C18 column (25 cm x $4.6 \mathrm{~mm}, 5 \mu \mathrm{m})$ at a column temperature of $30^{\circ} \mathrm{C}$. The mobile phase was composed of two parts: (A) $0.5 \%$ acetic acid in water and $(\mathrm{B})$ acetonitrile. The gradient program was run as follows: $0-25 \mathrm{~min}, 5 \% \mathrm{~B} ; 25-30$ min, 25-40\% B; 30-40 min, 40-100\% B; 40-55 min, and $100-5 \% \mathrm{~B}$. The flow rate was set at $1 \mathrm{~mL} / \mathrm{min}$ and the injection volume was $10 \mu \mathrm{L}$.

\section{Quantification of Geniposide, Berberine, and Baicalin in HHT and HHT-AuNPs}

As the marker compounds of HHT are geniposide, berberine, and baicalin, their contents in HHT were quantitatively analyzed. ${ }^{23}$ The powdered extract of HHT (2.4 $\mathrm{mg})$ and HHT-AuNPs (1.5 $\mathrm{mg})$ were dissolved in $0.8 \mathrm{~mL}$ and $0.5 \mathrm{~mL}$ of $\mathrm{MeOH}$, respectively. HHT and HHT-AuNPs (3 $\mathrm{mg} / \mathrm{mL}$ ) were placed in an ultrasonic bath for $20 \mathrm{~min}$. The suspension was then diluted 1000 times and filtered with a $0.45 \mu \mathrm{m}$ PVDF membrane filter. The supernatant was used for HPLC analysis. The standard compounds ( $1 \mathrm{mg}$ of geniposide, baicalin, or berberine) were dissolved in $1 \mathrm{~mL} \mathrm{MeOH}$ and processed under the same conditions. The correlation coefficients (R2) of the marker compounds in HHT showed good linearity $(\geq 0.9995$, Supplementary Figure S1 and S2).

\section{Preparation and Optimization of HHT-AuNPs}

To synthesize AuNPs, the optimized conditions were monitored as described earlier. ${ }^{29}$ HHT extract was dissolved in distilled water at a concentration of $10 \mathrm{mg} / \mathrm{mL}$ and passed through a $0.22 \mu \mathrm{m}$ filter before use. The gold salt $\left(\mathrm{HAuCl}_{4}\right.$ $\cdot 3 \mathrm{H}_{2} \mathrm{O}$ ) was dissolved in distilled water and used at 100 $\mathrm{mM}$ (stock solution). The stock solution of gold salt was added to the HHT solution at different concentrations. The reaction mixtures were incubated in a shaking incubator (MSH-20A, DAIHAN Scientific, Republic of Korea). We 
optimized the conditions for the synthesis of HHT-AuNPs in terms of $\mathrm{HHT}$ and $\mathrm{HAuCl}_{4} \cdot 3 \mathrm{H}_{2} \mathrm{O}$ concentrations, incubation time, and reaction $\mathrm{pH}$. The synthesis was first monitored by the visual color change of the reaction mixture, followed by spectral analysis. After the complete reduction of the gold salt $(1.5 \mathrm{mM})$ into the nanoparticles, the nanoparticles were collected by centrifugation at 12,000 rpm for 20 min (Smart R17 Plus, Hanil Scientific Inc., Republic of Korea). The obtained nanoparticles were washed thoroughly with distilled water to remove unconverted metal ions or other constituents. Finally, the nanoparticles were collected by air-drying and used for analytical characterization and application.

\section{Characterization of the HHT-AuNPs}

An UV-Vis spectrophotometer (Cary 60; Agilent, Santa Clara, CA, USA) was used to confirm the absorbance spectra of the purified nanoparticle suspension in the range of 300-800 $\mathrm{nm}$. Morphological observation, elemental mapping, SAED, and EDX of the AuNPs were performed. The sample was prepared by placing droplets of purified nanoparticles dispersed in water on a carboncoated copper grid and dried at $37^{\circ} \mathrm{C}$ before being transferred to the microscope. Field emission scanning electron microscopy (FE-SEM) was used to determine the morphology, purity, structure, and elemental distribution of HHT-AuNPs. Furthermore, the particle sizes were measured in water using dynamic light scattering (DLS, Otsuka Electronics, Shiga, Japan).

Powder XRD patterns were recorded to characterize the crystal structures of the synthesized nanoparticles. FTIR spectra of the dried HHT-AuNPs were acquired using a Spectrum ${ }^{\mathrm{TM}}$ One FTIR Spectrometer (PerkinElmer, Waltham, MA, USA) to identify the possible functional groups of the plant extract capped on the surfaces of the AuNPs.

\section{Animals and Husbandry}

Four-week-old male ICR mice weighing 28-30g were procured from Orient Bio, Inc. (Seongnam, Republic of Korea). The mice were housed in a humidity-controlled room with a 12-h/12-h light-dark cycle at a temperature of $23 \pm 2{ }^{\circ} \mathrm{C}$, with food and water provided ad libitum. All experimental procedures for animal studies were reviewed and approved by the Institutional Animal Care and Use Committee at Kyung Hee University (KHUASP(SE)-14040) and performed following the Principles of Laboratory Animal Care (NIH publication, \#85-23, revised in 1985).

\section{Cell Culture}

For in vitro experiments, RAW264.7 cells were obtained from the Korean Cell Line Bank (Seoul National University, Seoul, Korea) and maintained in DMEM (high glucose) supplemented with $10 \% \mathrm{FBS}$ at $37^{\circ} \mathrm{C}$ in a humidified incubator supplied with $5 \% \mathrm{CO}_{2}$. The MTT assay was used to perform cytotoxicity analysis. Briefly, RAW264.7 cells $\left(1 \times 10^{4}\right.$ cells/well $)$ were seeded in 96-well plates and incubated for 24 h. Cytotoxicity was analyzed after cells were treated with various concentrations of samples for $24 \mathrm{~h}$. LPS $(1 \mu \mathrm{g} / \mathrm{mL})$ was used as a positive control. MTT solution $(0.5 \mathrm{mg} / \mathrm{mL}, 100$ $\mu \mathrm{L})$ was added to cells and further incubated for approximately $3 \mathrm{~h}$ at $37^{\circ} \mathrm{C}$. The resulting formazan crystal was dissolved in DMSO $(100 \mu \mathrm{L})$, and the absorbance was measured at $570 \mathrm{~nm}$ using a microplate reader (Molecular Devices Filter Max F5; San Francisco, CA, USA).

For ex vivo experiments, spleen tissues were aseptically removed from the mice to obtain splenocytes as described by Noh et al with minor modifications. ${ }^{30}$ Briefly, the spleen was gently cut into small pieces with surgical scissors and filtrated through a $70-\mu \mathrm{m}$ cell strainer (SPL Life Sciences, Pocheon-si, Gyeonggi-do, Korea). The cells were dissolved in red blood cell lysis buffer (Sigma-Aldrich, St. Louis, MO, USA) to remove red blood cells. Isolated splenocytes were incubated in RPMI 1640 medium supplemented with $10 \%$ FBS and $1 \%$ penicillin-streptomycin at $37^{\circ} \mathrm{C}$ in a humidified incubator supplied with $5 \% \mathrm{CO}_{2}$. The suspended cells were collected after incubation for $3 \mathrm{~h}$ to obtain the splenocytes. Splenocytes $\left(2 \times 10^{5}\right.$ cells/well $)$ were seeded in 96-well plates, treated with samples at various concentrations, and incubated for $12,24,36$, or $48 \mathrm{~h}$ at $37^{\circ} \mathrm{C}$ in a humidified incubator supplied with $5 \% \mathrm{CO}_{2}$. Cell viability was measured using a WST- 8 assay kit and a microplate reader (Molecular Devices Filter Max F5; San Francisco, CA, USA), according to the manufacturer's protocol.

\section{Uptake and Intracellular Localization of HHT-AuNPs}

After treatment, the RAW264.7 cells were washed three times with PBS to remove unbound nanoparticles. The cells were processed, as described by Liu et al, with minor modifications. ${ }^{28}$ Briefly, the collected cell pellets were fixed using $2.5 \%$ glutaraldehyde at $4^{\circ} \mathrm{C}$ for $8 \mathrm{~h}$, postfixed with $1 \%$ osmium tetroxide for $2 \mathrm{~h}$, and gradually dehydrated with $50 \%, 70 \%, 90 \%$, and $100 \%$ ethanol for 15 min each. The samples were then embedded in Epon 
(Sigma-Aldrich) and ultrathin sections $(70 \mathrm{~nm})$ were obtained using an ultramicrotome (Leica EM UC7, Wetzlar, Germany). The samples were post-treated following a standard protocol for Bio-TEM imaging. Finally, the sections were imaged using JEM-1010 TEM (JEOL, Tokyo, Japan) operated at $80 \mathrm{kV}$.

\section{Live/Dead Fluorescent Assay and Hoechst 33258 Staining}

To evaluate the cytotoxic effect of sample, RAW264.7 cells were placed at a density of $2.0 \times 10^{5}$ cells/well into a 6-well culture plate and stabilized approximately a day until $70-80 \%$ confluence. After the culture medium was removed by rinsing PBS twice, and fresh medium containing various concentrations of sample was added to the cells. Following further incubation for $24 \mathrm{~h}$, the cells were than stained with a live/dead cell staining kit and a Hoechst 33258 dye solution according to the manufacturers' protocols. After incubation at $37^{\circ} \mathrm{C}$ in the dark place for $30 \mathrm{~min}$, the stained cells were visualized using a fluorescence scanning microscope (Leica, Wetzlar, Germany) at Ex/Em of 490/525 nm.

\section{Nitric Oxide Determination}

RAW264.7 cells $\left(1 \times 10^{4}\right.$ cells/well $)$ were seeded in 96 well plates and treated with samples for $24 \mathrm{~h}$. The production of nitrite $\left(\mathrm{NaNO}_{2}\right)$, a stable end-product of nitric oxide (NO) oxidation, was determined using Griess reagent according to the manufacturer's protocol. The culture supernatant $(100 \mu \mathrm{L})$ was reacted with $100 \mu \mathrm{L}$ Griess reagent. After $30 \mathrm{~min}$ incubation, the absorbance was measured using a spectrophotometric microplate reader (Molecular Devices Filter Max F5; San Francisco,
CA, USA) at $575 \mathrm{~nm}$. The standard curve of sodium nitrite was used to estimate the concentration of $\mathrm{NaNO}_{2}$.

\section{Quantitative Real-Time Polymerase Chain Reaction (qRT-PCR)}

mRNA expression was quantified using qRT-PCR. Briefly, total cellular RNA was extracted using the TRIzol reagent (Invitrogen, Carlsbad, CA, USA). Then, 500 ng RNA was reverse-transcribed to single-strand cDNA using the Superscript First-Strand Synthesis Kit (Invitrogen, Carlsbad, CA, USA). Following the manufacturer's instructions, qRT-PCR was performed on the CFX96TM Real-Time RT-PCR System using the SYBR ${ }^{\circledR}$ Premix Ex TaqII RT-PCR Kit (TaKaRa, Japan). The assay was conducted using $50 \mathrm{ng}$ cDNA in a $20 \mu \mathrm{L}$ reaction volume with amfiSure qGreen Q-PCR Master Mix (GenDEOT, TX, USA). The primer sequences (forward and reverse) used for qRT-PCR are listed in Table 1. Each sample was analyzed in triplicate. Gene expression was normalized to that of an endogenous control (GAPDH).

\section{Enzyme-Linked Immunosorbent Assay (ELISA)}

After cells were treated with samples, as described in the previous section, the RAW264.7 cell culture supernatant $(100 \mu \mathrm{L})$ was collected, and the levels of TNF- $\alpha$ and IL-1 $\beta$ were determined using ELISA kits (R\&D Systems, MN, USA), according to the manufacturer's instruction. Furthermore, the splenocyte culture supernatant was used to assess the secretions of TNF- $\alpha$, IL- $1 \beta$, IL- 2 , and IFN- $\gamma$ using respective ELISA kits (R\&D Systems, Minneapolis, MN, USA), and the levels of immunoglobulin G (IgG) and immunoglobulin A (IgA) were determined using the

Table I Primer Sequences Used for qRT-PCR Analysis in This Study

\begin{tabular}{|c|c|c|}
\hline Primer & & Sequence $\left(5^{\prime}-3^{\prime}\right)$ \\
\hline IL-6 & Forward; Reverse & 5'-GTTCTCTGGGAAATCGTGGA-3'; 5'-TGTACTCCAGGTAGCTATGG-3' \\
\hline TNF- $\alpha$ & Forward; Reverse & 5'-AGCCCACGTCGTAGCAAACCAC-3'; 5'-AACACCCATTCCCTTCACAG-3' \\
\hline IL-I $\beta$ & Forward; Reverse & 5'-TGCAGAGTTCCCCAACTGGTAC-3'; 5'-GTGCTGCCTAATGTCCCCTT-3' \\
\hline iNOS & Forward; Reverse & 5'-AATGGCAACATCAGGTCGGCCA-3'; 5'-GCTGTGTGTCACAGAAGTCT-3' \\
\hline IL-10 & Forward; Reverse & 5'-TAGAGCTGCGGACTGCCTTCA-3'; 5'-GGTCTTCAGCTTCTCACCCAG-3' \\
\hline Arg-I & Forward; Reverse & 5'-ACTGAGGAATGCTGGTCTGGT-3'; 5'-GCTTCCAACTGCCATACTGTGG-3' \\
\hline IL-4 & Forward; Reverse & 5'-TGATCACAACATTGCATTTCA-3'; 5'-ACACCAGATTGTCAGTCACTTG-3' \\
\hline IL-13 & Forward; Reverse & 5'-CCAGAAGGTGAGTGTCGGCTA-3'; 5'-CTAACGAATCCTCCTGTAAGG-3' \\
\hline IFN- $\gamma$ & Forward; Reverse & 5'-TATCTCTTTCTACCTCAGAC-3'; 5'-GCAATCACAGTCTTGGCTAATTAG-3' \\
\hline IL-2 & Forward; Reverse & 5'-CCTGAGCAGGATGGAGAATTA-3'; 5'-TCCAGAACATGCCGCAGAG-3' \\
\hline GAPDH & Forward; Reverse & 5'-ACCACAGTCCATGCCATCAC-3'; 5'-CCACCACCCTGTTGCTGTAG-3' \\
\hline
\end{tabular}


mouse IgG and IgA ELISA kits (Elabscience, Texas, USA), respectively.

\section{Western Blotting}

After treatment, RAW264.7 cell pellets were collected and lysed in Pierce ${ }^{\mathrm{TM}}$ RIPA Buffer (Thermo Scientific, USA) for $1 \mathrm{~h}$. The cell lysates were centrifuged for $20 \mathrm{~min}$ at $12,000 \mathrm{rpm}$ at $4^{\circ} \mathrm{C}$, and the total protein was collected from the supernatant. A Bio-Rad Protein Assay Kit (BioRad Laboratories Inc., Hercules, CA, USA) was used to determine the protein concentration. Equal amounts (50 $\mu \mathrm{g}$ ) of total protein were subjected to the sodium dodecyl sulfate polyacrylamide (SDS-PAGE; 10\% gel). The separated proteins were transferred to PVDF membranes (Thermo Fisher Scientific, USA) using the Protein Gel Electrophoresis Chamber System (Thermo Fisher Scientific, USA). The membranes were blocked with 5\% nonfat milk at room temperature for $1 \mathrm{~h}$ and then incubated overnight at $4^{\circ} \mathrm{C}$ with primary antibodies (1: 1000). After washing three times with phosphate-buffered salineTween 20 (PBS-T), the membranes were incubated with the appropriate HRP-conjugated secondary antibody (1:5000) for $1 \mathrm{~h}$ in the dark. The immunoreactive bands were developed using West-Q Pico ECL Solution (GenDEPOT, Katy, TX, USA), visualized using an Alliance MINI HD9 AUTO Immunoblot Imaging System (UVItec Limited, England, UK), and quantified using the ImageJ software.

\section{Statistical Analysis}

Qualitative data shown in this study are representative of at least three separate experiments. Quantitative data are expressed as mean \pm standard deviation (SD). One-way ANOVA and Student's $t$-test were performed to determine the statistical significance between groups. GraphPad Prism 6 was used to perform the statistical analysis. Results with $p<0.05$ and $p<0.01$ were considered statistically significant.

\section{Results and Discussion Synthesis and Optimization of HHT-AuNPs}

The procedure for preparing HHT-AuNPs is shown in Figure 1A. The optimal synthesis conditions were established using the same methods described previously to synthesize AuNPs from plant extracts. ${ }^{19,31} \mathrm{UV}-$ Vis spectroscopy was used to monitor the visible absorption spectrum of the nanoparticles. As shown in Figure 1B, the formation of AuNPs was confirmed using UV-Vis spectral analysis and color change under different conditions. Figure 1B(a) illustrates the effects of HHT concentrations on the formation of HHT-AuNPs. When different concentrations $(0.08,0.16,0.31,0.63,1.25,2.5,5$, and $10 \mathrm{mg} / \mathrm{mL}$ ) of HHT and $1 \mathrm{mM} \mathrm{HAuCl}{ }_{4} \cdot 3 \mathrm{H}_{2} \mathrm{O}$ at $\mathrm{pH} 4.0$ were reacted at ambient temperature $\left(25^{\circ} \mathrm{C}\right)$, surface plasmon wavelengths of AuNPs were observed at $551 \mathrm{~nm}$, albeit with a slow reduction rate; the total reaction times of AuNPs synthesis was 40 min. The synthesized AuNPs showed a similar absorbance from 2.5 to $10 \mathrm{mg} / \mathrm{mL}$ concentrations of HHT extract. A lower concentration $(2.5 \mathrm{mg} / \mathrm{mL})$ was more suitable and cost-effective for biological applications. Therefore, $2.5 \mathrm{mg} / \mathrm{mL}$ HHT was selected to optimize the reaction temperature further. As shown in Figure $1 \mathrm{~B}(\mathrm{~b})$, when $2.5 \mathrm{mg} / \mathrm{mL}$ HHT and $1 \mathrm{mM}$ $\mathrm{HAuCl}_{4} \cdot 3 \mathrm{H}_{2} \mathrm{O}$ at $\mathrm{pH} 4.0$ were reacted at different temperatures $\left(20^{\circ} \mathrm{C}, 30^{\circ} \mathrm{C}, 40^{\circ} \mathrm{C}, 50^{\circ} \mathrm{C}\right.$, and $\left.60^{\circ} \mathrm{C}\right)$ for $40 \mathrm{~min}$, the optimal production of HHT-AuNPs was observed at $40^{\circ} \mathrm{C}$. Figure $1 \mathrm{~B}(\mathrm{c})$ illustrates the effect of reaction time on the formation of HHT-AuNPs. When $2.5 \mathrm{mg} / \mathrm{mL}$ HHT and $1 \mathrm{mM} \mathrm{HAuCl}{ }_{4} \cdot 3 \mathrm{H}_{2} \mathrm{O}$ at $\mathrm{pH} 4.0$ were reacted at $40^{\circ} \mathrm{C}$ for different reaction times $(10,20,30,40,50$, and $60 \mathrm{~min})$, the synthesized HHT-AuNPs had a similar absorption spectrum. A reaction time of $30 \mathrm{~min}$ was selected to optimize the $\mathrm{HAuCl}_{4} \cdot 3 \mathrm{H}_{2} \mathrm{O}$ concentration further. As shown in Figure $1 \mathrm{~B}(\mathrm{~d}), 2.5 \mathrm{mg} / \mathrm{mL}$ HHT and different concentrations of $\mathrm{HAuCl}_{4} \cdot 3 \mathrm{H}_{2} \mathrm{O}(0.25,0.5,1,1.5,2$, and $2.5 \mathrm{mM}$ ) at $\mathrm{pH} 4.0$ were reacted at $40^{\circ} \mathrm{C}$ for $30 \mathrm{~min}$. When $\mathrm{HAuCl}_{4} \cdot 3 \mathrm{H}_{2} \mathrm{O}$ concentration was $1.5 \mathrm{mM}$, major absorption peaks at $551 \mathrm{~nm}$ were more significant. Finally, HHTAuNPs were synthesized using HHT $(2.5 \mathrm{mg} / \mathrm{mL})$ and $\mathrm{HAuCl}_{4} \cdot 3 \mathrm{H}_{2} \mathrm{O}(1.5 \mathrm{mM})$ at different $\mathrm{pH}(2.0,3.0,4.0$, 5.0, 6.0, and 7.0) at $40^{\circ} \mathrm{C}$ for $30 \mathrm{~min}$. As shown in the Figure $1 \mathrm{~B}(\mathrm{e})$, the major absorption peaks at $551 \mathrm{~nm}$ were more significant when the reaction $\mathrm{pH}$ was 3.0. Therefore, our results exhibited that when $2.5 \mathrm{mg} / \mathrm{mL}$ HHT and 1.5 $\mathrm{mM} \mathrm{HAuCl}{ }_{4} \cdot 3 \mathrm{H}_{2} \mathrm{O}$ in a solution at $\mathrm{pH} 3.0$ were reacted at $40^{\circ} \mathrm{C}$ for $30 \mathrm{~min}$, HHT-AuNPs exhibited the best production.

\section{Characterization of HHT-AuNPs}

Under optimal conditions, we synthesized and characterized the HHT-AuNPs using UV-Vis spectrophotometry as shown in Figure 2A. The $\lambda_{\max }$ was observed at $551 \mathrm{~nm}$ for HHT-AuNPs, which indicated the response of surface plasmon resonance caused by the oscillation of free 

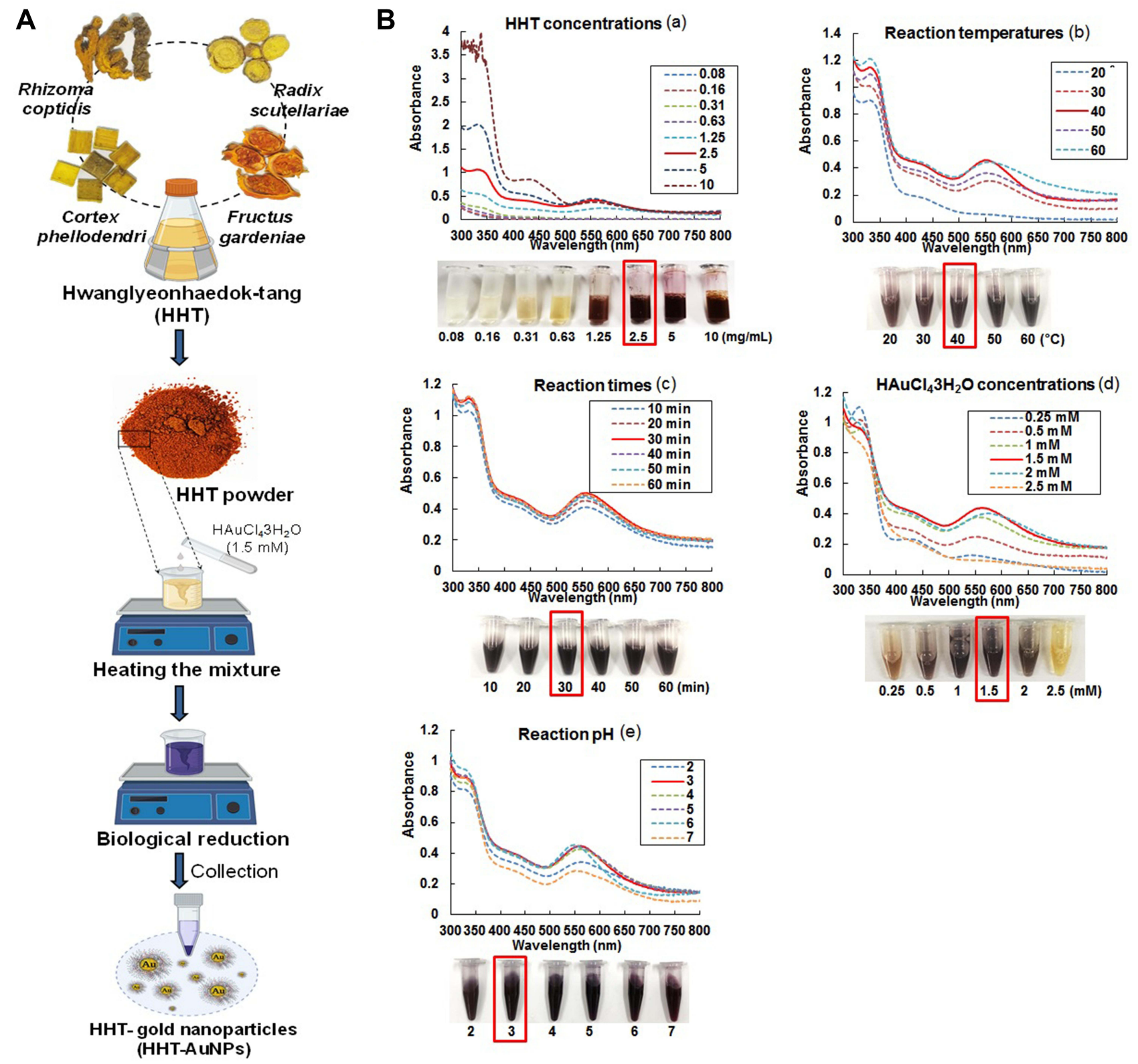

Figure I Synthesis and optimization of HHT-AuNPs. (A) Schematic illustration of AuNPs synthesis using HHT; (B) optimization of reaction condition, including HHT concentration (a), temperature (b), reaction time (c), gold salt concentration (d), and $\mathrm{pH}(\mathrm{e})$ for the large-scale bioreduction of $\mathrm{HAuCl}_{4} \cdot 3 \mathrm{H}_{2} \mathrm{O}$.

electrons in the conduction band of the formed AuNPs. ${ }^{32}$ Elbagory et al reported that the AuNPs synthesized from Hypoxis hemerocallidea extract showed a similar absorption maximum within the visible spectrum range (500-600 $\mathrm{nm}) .{ }^{19}$ Additionally, the color changed from light yellow to deep purple. These data demonstrated the successful synthesis of HHT-AuNPs.

The structural properties (size and morphology) of the synthesized HHT-AuNPs were determined using three independent analyses (FE-TEM, FE-SEM, and DLS). As shown in Figure 2B, the FE-TEM revealed that the particle sizes varied from 6 to $74 \mathrm{~nm}$, with spherical and polygonal morphologies (a). Elemental mapping detected the discernible distribution of gold (green color) in the purified particles (b). EDX analysis demonstrated the highest characteristic peaks of metallic gold at $2.2 \mathrm{keV}$ (c). FE-SEM showed the compact spherical morphologies and aggregation due to the high surface energy of AuNPs (Figure 2C (a)). The gold distribution was also detected by elemental mapping (Figure $2 \mathrm{C}(\mathrm{b})$, green color), corresponding to the TEM results. SAED and XRD patterns showed four major diffraction peaks at $2 \theta$ values of $38.12^{\circ}, 44.53^{\circ}, 64.68^{\circ}$ 

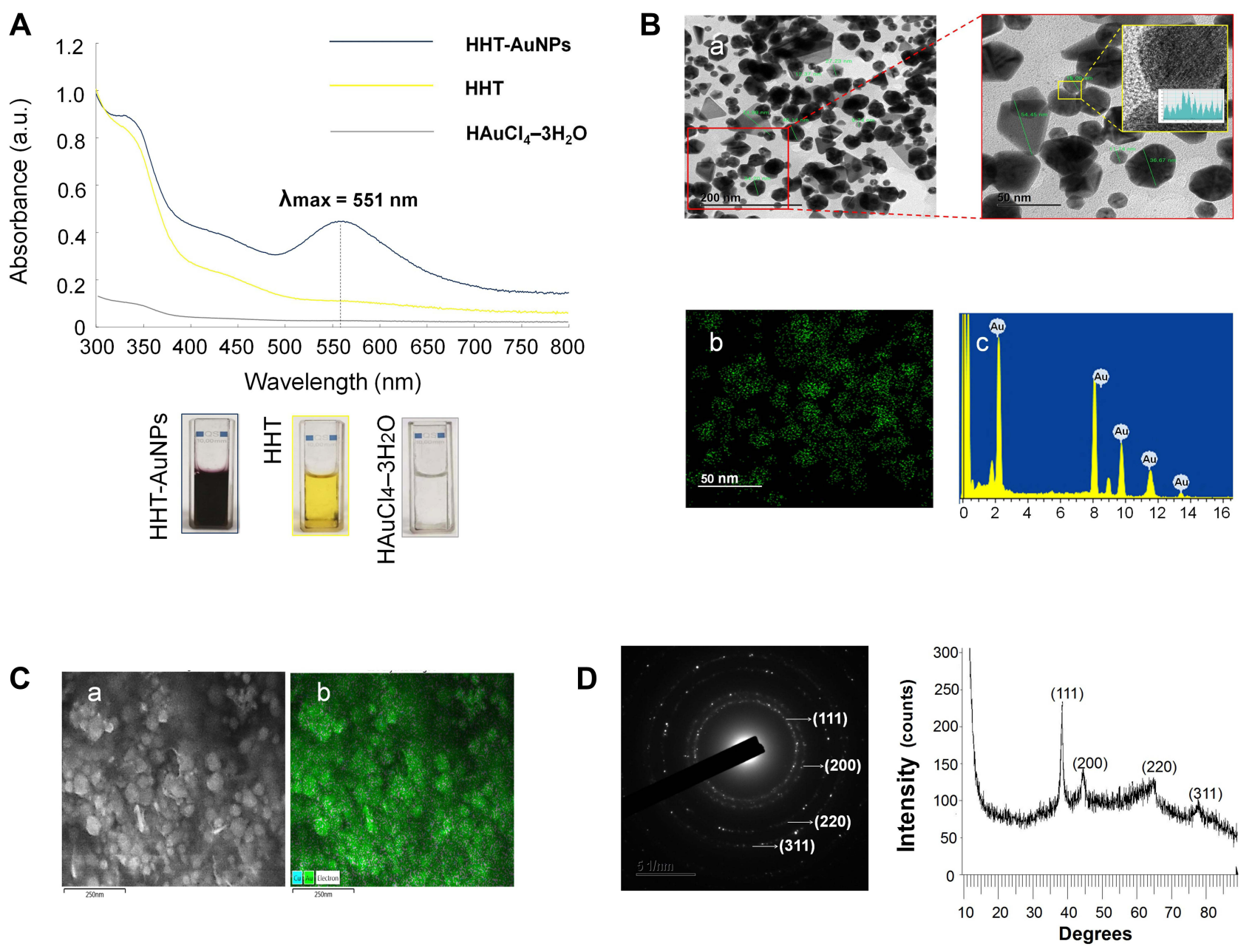

E

Intensity Distribution

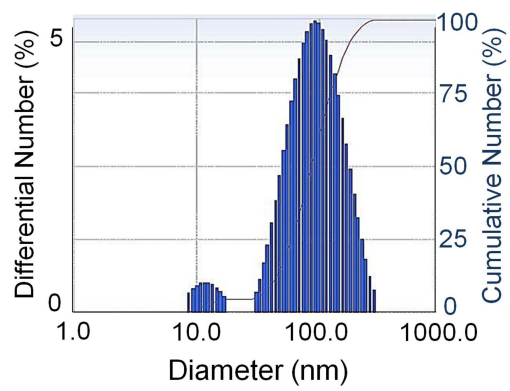

Number Distribution

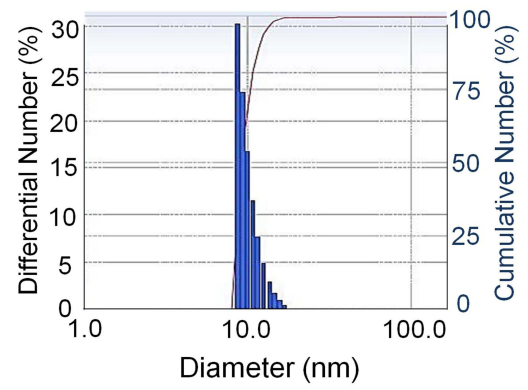

Volume Distribution

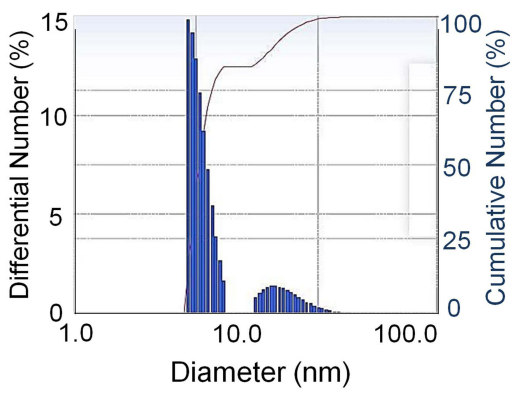

Figure 2 Characterization of HHT-AuNPs. (A) UV-Vis absorption spectroscopy analysis of synthesized HHT-AuNPs and HHT; (B) TEM micrograph of HHT-AuNPs in which the scale bar represents $200 \mathrm{~nm}, 50 \mathrm{~nm}$ and $5 \mathrm{~nm}$ (a); Gold distribution (elemental mapping, b) and energy-dispersive X-ray spectroscopy analysis (EDX, c); (C) FESEM pattern (a) and gold distribution (b) of HHT-AuNPs; (D) selected area diffraction pattern (left) and X-ray diffraction (XRD) pattern (right); (E) size distribution of the nanoparticles using dynamic light scattering (DLS) with respect to intensity, number, and volume.

and $77.93^{\circ}$, which correspond to four characteristic peaks of gold at the (111), (200), (220), and (311) lattice planes of Bragg's reflection, respectively (Figure 2D). ${ }^{33}$ These findings are consistent with our previous report, wherein the four characteristic peaks of gold corresponded to the (111), (200), (220), and (311) lattice planes of Bragg's reflection, and four diffraction peaks of Euphrasia officinalis leaf extract-mediated AuNPs were displayed at the $2 \theta$ values of $38.11^{\circ}, 45.15^{\circ}, 64.65^{\circ}$, and $77.93^{\circ} .{ }^{29}$ Using a particle size analyzer, the DLS method was employed to calculate the size distribution profile of the HHT-AuNPs with respect to intensity, number, and volume. As shown 
in Figure 2E, the average intensity, number, and volume values were $106,19.2$, and $10.3 \mathrm{~nm}$, respectively. The hydrodynamic diameter of HHT-AuNPs was $91.3 \mathrm{~nm}$ with a moderate polydispersity index (PDI) of 0.25 $(<0.3)$, which indicated a narrow size distribution of AuNPs. ${ }^{34}$ The HHT-AuNPs had a zeta potential of $-30.06 \mathrm{mV}$. DLS takes the organic shell into account for determining the entire size of the conjugates in the colloids or their average hydrodynamic size. The number of biomolecules covering each NP in the colloids was large; therefore, the hydrodynamic size measured using DLS was greater than the size measured using TEM. ${ }^{35}$ Metallic nanoparticles show different tumor-targeting abilities depending on the particle size. Nanoparticles smaller than $20 \mathrm{~nm}$ exhibit low tumor-specific accumulation, whereas nanoparticles larger than $300 \mathrm{~nm}$ are easily eliminated by phagocytosis. In contrast, nanoparticles in the size range of $50-200 \mathrm{~nm}$ are highly recommended for tumor accumulation. ${ }^{36}$ This finding suggests that HHTAuNPs may be advantageous for cancer immunotherapy.

FTIR spectra identified the possible functional groups on the surfaces of HHT-AuNPs (Figure 3A); the absorption peaks are illustrated in Figure 3B. The HHT-AuNPs and HHT showed bands at 3423.55 and $3256.49 \mathrm{~cm}^{-1}$, respectively, and were characterized as $\mathrm{O}-\mathrm{H}$ stretching, at 2850.05-2920.84 $\mathrm{cm}^{-1}$, which correspond to $\mathrm{C}-\mathrm{H}$ stretching, in the range of $1508.14-1635.81 \mathrm{~cm}^{-1}$. This stretching was represented as $\mathrm{C}=\mathrm{O}$ and $\mathrm{C}=\mathrm{C}$ double-bond functional groups, at $1018.61-1362.10 \mathrm{~cm}^{-1}$, corresponding to the $\mathrm{C}-\mathrm{C}$ and $\mathrm{C}-\mathrm{O}$ bands, in the range from 518.29 to $768.16 \mathrm{~cm}^{-1}$, which was represented by the deformation vibration of $=\mathrm{CH}$ functional bonds. ${ }^{29}$ These results suggested that HHT-AuNPs were composed of a mixed structure comprising individual $\mathrm{HAuCl}_{4} \cdot 3 \mathrm{H}_{2} \mathrm{O}$ and $\mathrm{HHT}$. Furthermore, thermogravimetric analysis (TGA) curves of HHT-AuNPs and HHT were obtained to whether the polymer grafted onto the surface. HHT (63.74\%) degraded to a greater degree than its corresponding HHT-AuNP (15.62\%), exhibiting two distinct degradation regions (Figure 3C). These results verified the formation of organic polymer coatings on the surface of HHT-AuNPs. $\mathrm{HAuCl}_{4} \cdot 3 \mathrm{H}_{2} \mathrm{O}$

\section{Quantification of Geniposide, Baicalin, and Berberine in HHT and HHT-AuNPs}

The marker compounds of HHT were analyzed using HPLC. As shown in Supplementary Figure S3 and S4, the characteristic peaks of geniposide, baicalin, and berberine were observed in HHT, but only baicalin and berberine peaks were detected in HHT-AuNPs. The contents of marker compounds in HHT extract were iridoids (geniposide $60.92 \pm 0.23 \mathrm{mg} / \mathrm{g}$ ); flavonoids (baicalin $17.29 \pm$ $0.85 \mathrm{mg} / \mathrm{g}$ ); alkaloids (berberine $21.53 \pm 0.17 \mathrm{mg} / \mathrm{g}$ ), whereas the contents of major compounds in HHTAuNPs were baicalin $(4.41 \pm 0.06 \mathrm{mg} / \mathrm{g})$ and berberine $(2.97 \pm 0.06 \mathrm{mg} / \mathrm{g})$ (Table 2). Plant flavonoids and alkaloids possess various functional groups capable of reducing metal ions into nanoparticles. ${ }^{27}$ These results revealed the presence of flavonoids and alkaloids on the HHTAuNPs surface, which could be attributable for the
A

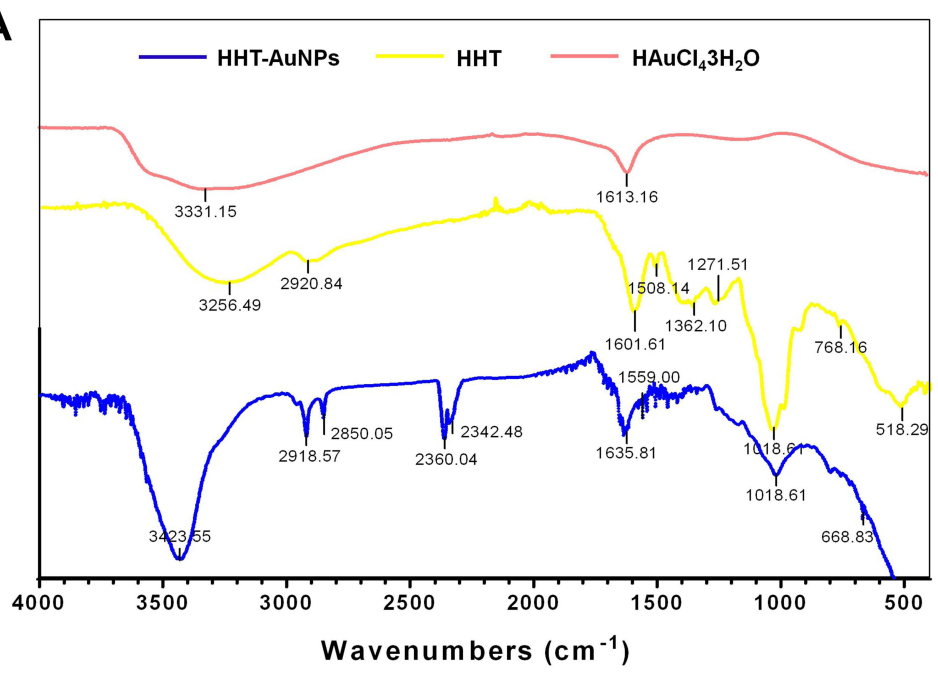

B

\begin{tabular}{ccc}
\hline Type of bond & $\begin{array}{c}\text { HHT-AuNPs } \\
\text { Wavenumber (cm-1) }\end{array}$ & $\begin{array}{c}\text { HHT } \\
\text { Wavenumber }(\mathrm{cm}-1)\end{array}$ \\
\hline O-H stretch & 3423.55 & 3256.49 \\
C-H stretch & $2918.57,2850.05$ & 2920.84 \\
C=C, C=O stretch & $1635.81,1559.00$ & $1601.61,1508.14$ \\
C-C, C-O stretch & 1018.61 & $1362.10-1018.61$ \\
$=$ CH & 668.83 & $768.16,518.29$ \\
\hline
\end{tabular}

C

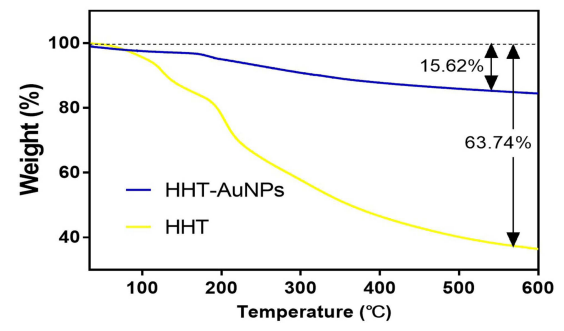

Figure 3 Complexation of HHT-phytochemicals onto the surface of HHT-AuNPs. (A) FTIR spectra of HHT and HHT-AuNPs; (B) a tabular view of the functional group profile; (C) thermogravimetric analysis (TGA) curves of HHT and HHT-AuNPs. 
Table 2 The Contents of Marker Compounds in HHT Extract and HHT-AuNPs

\begin{tabular}{|l|l|l|l|}
\hline Components & Geniposide & Baicalin & Berberine \\
\hline HHT (mg/g) & $60.92 \pm 0.23$ & $17.29 \pm 0.85$ & $21.53 \pm 0.17$ \\
HHT-AuNPs (mg/g) & 0 & $4.41 \pm 0.06$ & $2.97 \pm 0.06$ \\
\hline
\end{tabular}

reduction of $\mathrm{HAuCl}_{4} \cdot 3 \mathrm{H}_{2} \mathrm{O}$ to AuNPs and further their stabilization. Although the main active compounds bound to nanoparticles were less than $10 \%$, the actual activity was 100 times higher in the same amount. Thus, the increased intracellular activity of natural substances could lead to maximum activity with a minimum amount of natural substances, and highly active but toxic compounds can reduce toxicity and increase intracellular activity by one-pot synthesis of nanoparticles.

\section{Uptake and Cytotoxicity of HHT-AuNPs in Macrophages}

Immune cells are the first barriers to nanoparticle penetration into cells. ${ }^{37}$ A study exploring the interactions between phagocytes and HHT-AuNPs is undoubtedly of major interest. Therefore, we investigated the in vitro uptake and immunostimulatory activity (and the underlying mechanisms) of AuNPs using macrophages.

First, the subcellular localization of HHT-AuNPs was investigated using Bio-TEM imaging. As shown in Figure 4A, after $3 \mathrm{~h}$ incubation, NPs taken up by the cells mainly appeared in the endosomes where they formed relatively large and dense aggregates. Some NPs appeared in the cytoplasm outside the endosomes, which reflected the endosomal escape of particles, and may lead to further intracellular biological effects. These results suggested that macrophages internalized HHT-AuNPs via endocytosis. Many researchers have investigated the mechanisms underlying the uptake of AuNPs. AuNPs with hydrodynamic sizes below $100 \mathrm{~nm}$ could be phagocytosed and internalized through caveolae and clathrin. ${ }^{38}$ Therefore, it was speculated that the high biocompatibility of HHT-AuNPs may depend if their hydrodynamic sizes was below $100 \mathrm{~nm}$.

Next, the cytotoxicity of HHT-AuNPs on RAW264.7 cells was evaluated using the MTT assay to screen for the biologically safe HHT-AuNPs concentrations. The results showed no significant differences in cell viability between the control group (untreated cells) and the HHT-AuNPs or HHT-treatment groups at concentrations between 10 and $200 \mu \mathrm{g} / \mathrm{mL}$ (Figure 4B). The acceptable cytotoxicity of biomedical material was $75 \%$ toward mammalian cells, which suggested that HHT-AuNPs were non-toxic to normal cells at the indicated concentrations. Similar results were observed with live/dead and Hoechst 33258 staining. As shown in Figure 4C, LPS-induced significant degree of cell death compared to the control group, whereas HHTAuNPs were tolerated better in RAW264.7 cells. Thus, concentrations of 100 and $200 \mu \mathrm{g} / \mathrm{mL}$ were used in subsequent experiments to assess the immunostimulatory activity of HHT-AuNPs in RAW264.7 cells.

\section{The in vitro Immunostimulatory Activity of HHT-AuNPs on Macrophages}

Macrophages can respond to external stimuli by rapidly changing their physiology and becoming activated by releasing of cytokines. ${ }^{39}$ Based on the macrophage-like properties of RAW264.7 cells, we observed no morphological changes in the control group during analysis. Similar to LPS-induced cell activation, HHT-AuNPs induced cell differentiation (red arrow) with flat and elongated cells showing pseudopodia formation (Figure $5 \mathrm{~A}$ ). ${ }^{40}$

Activated macrophages induce inflammatory mediator expression, including immunity-related cytokines and $\mathrm{NO}$, that protect the body by recognizing and killing invading pathogens after a complex series of biological processes. ${ }^{1}$ Appropriate NO production is important for the immune system to achieve self-protection. ${ }^{41}$ Therefore, the effect of AuNPs on NO production in RAW264.7 cells was examined. As shown in Figure 5B, HHT-AuNPs considerably promoted NO production in a dose-dependent manner compared to the control group. However, the HHT-AuNPs -induced NO production was considerably lower than that of the LPS-treated control, confirming that HHT-AuNPs induced NO production rather than inflammation.

Cytokines significantly influence immune responses by regulating the differentiation and activation of macrophages. ${ }^{42}$ The cytokine levels in macrophages are often used to evaluate immunomodulatory capacity. IL- 6 , TNF- $\alpha$, and IL- $1 \beta$ are considered the most important proinflammatory cytokines that act on macrophages in an autocrine manner to strengthen various functional responses; moreover, they induce 
A

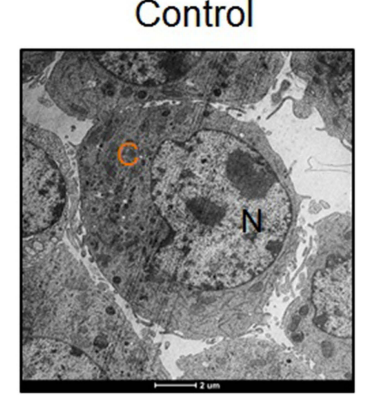

LPS

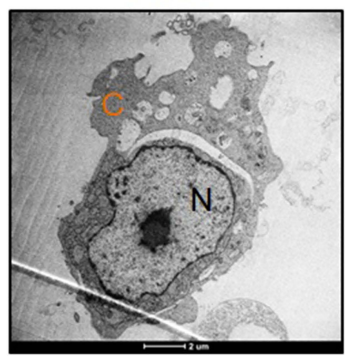

HHT-AuNPs

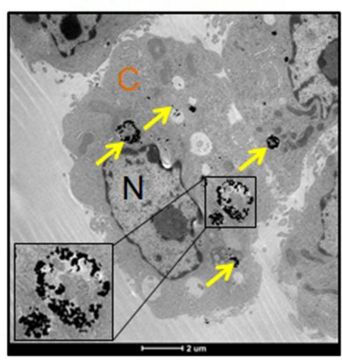

HHT

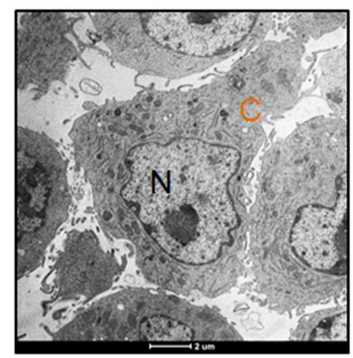

B

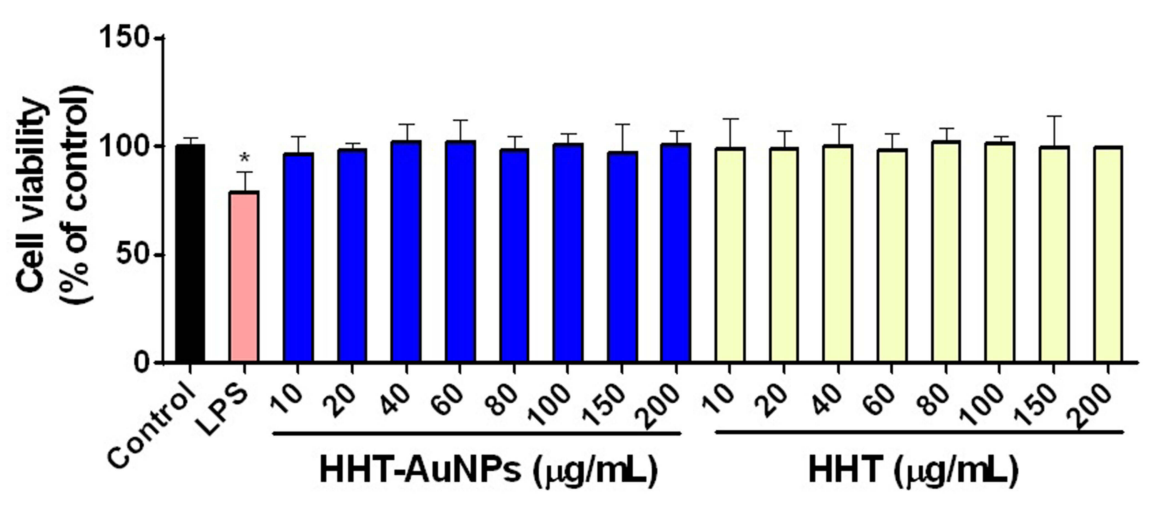

C
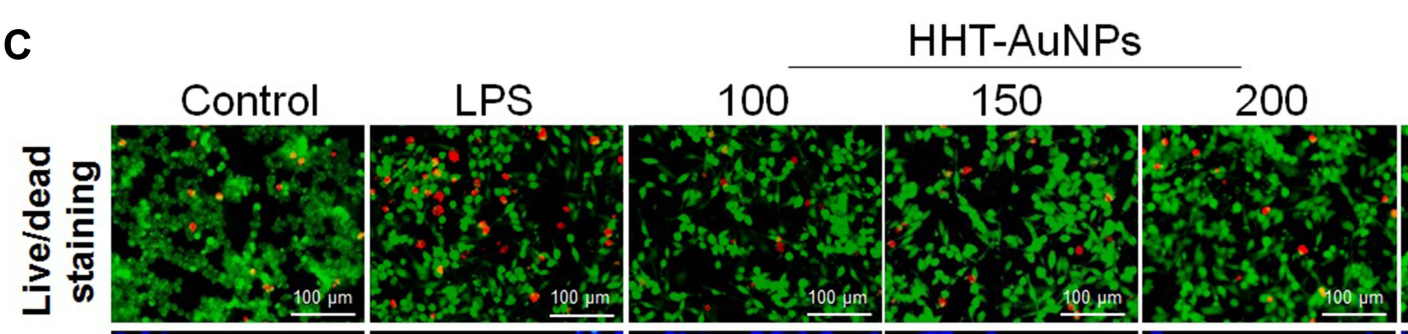

HHT
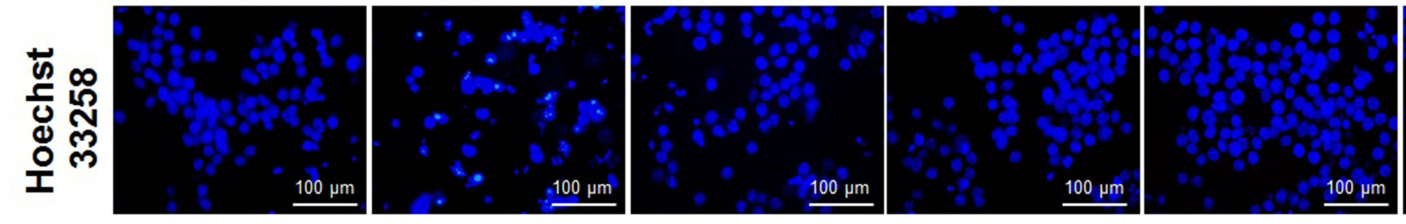
$200 \mathrm{ug} / \mathrm{mL}$

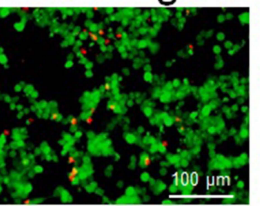

Figure 4 Uptake and cytotoxicity of HHT-AuNPs in macrophages. (A) Bio-TEM images, representative TEM images of HHT-AuNPs cellular uptake are presented in the enlarged images (lower) from the line squares, the yellow arrows pointed to accumulation of HHT-AuNPs, the "C" and "N" indicate nucleoplasm (N) and cytoplasm (C), respectively; (B) effects of HHT and HHT-AuNPs on viability in RAW264.7 cells; (C) fluorescent images of RAW264.7 cells following live/dead and Hoechst 33258 staining. All values are expressed as mean \pm S.D. ${ }^{*} p<0.05$ vs control group.

the expression of other immunoregulatory mediators, such as iNOS. ${ }^{43}$ In this study, we confirmed the upregulated expression of various immune-related genes in macrophages after HHTAuNPs treatment in a dose-dependent manner (Figure 5C). However, there is a subtle difference in the activation of the M1 and M2 macrophage phenotypes. Macrophages can be responsible for pro-inflammatory behavior (M1 cells) or anti- inflammatory activity (M2 cells) when exposed to various stimulators depending on their phenotypes; nevertheless, both M1 and M2 macrophages are closely related to immune responses. ${ }^{44}$ HHT-AuNPs $(200 \mu \mathrm{g} / \mathrm{mL})$ induced the expressions of $I L-6, T N F-\alpha, I L-1 \beta$, and $i N O S$ mRNA by 18.6 -fold, 1.7-fold, 14.2-fold, and 14.4-fold in macrophages, respectively (Figure $5 \mathrm{C}$ ). iNOS is a pivotal regulator for the majority of NO 

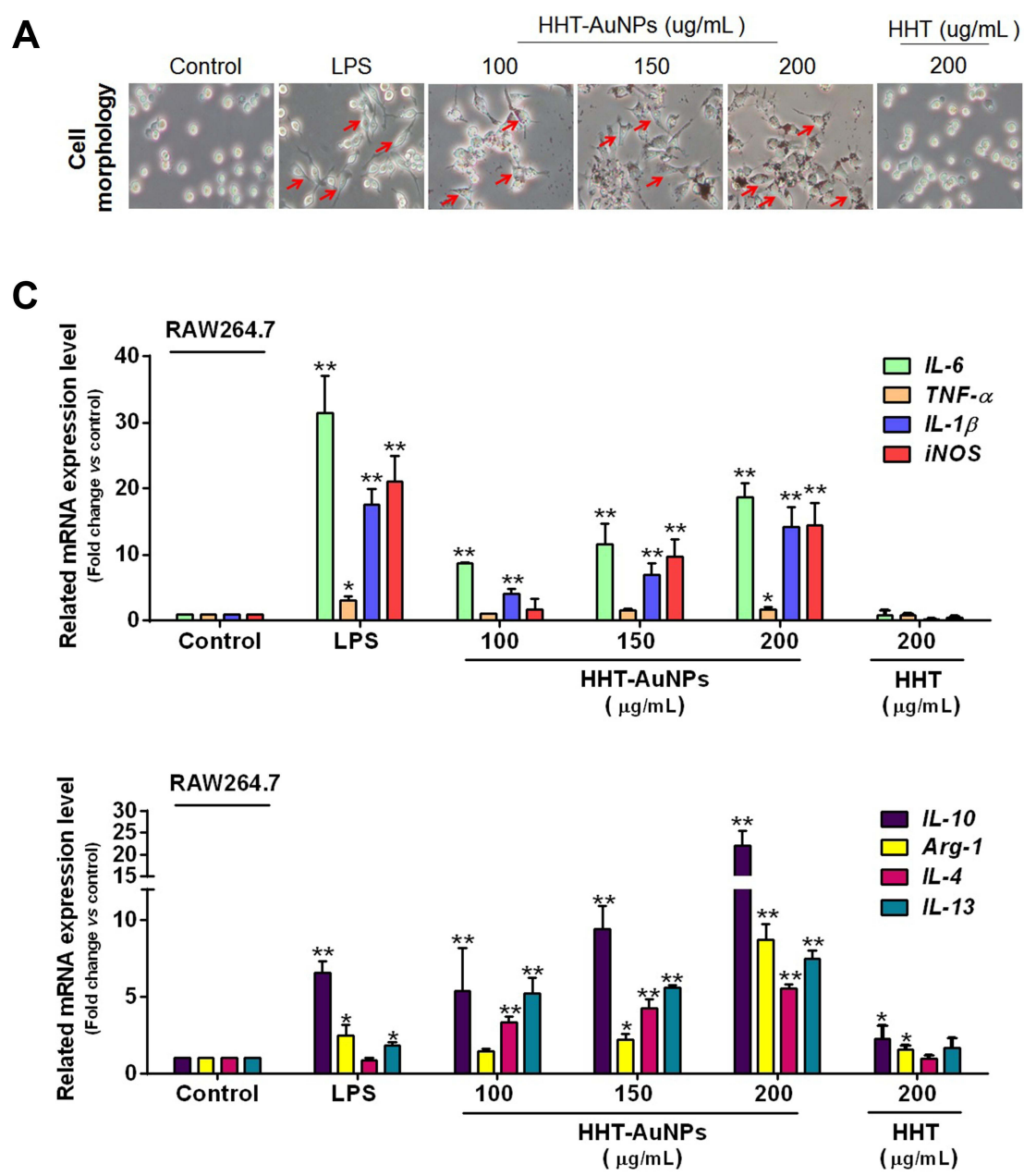

B
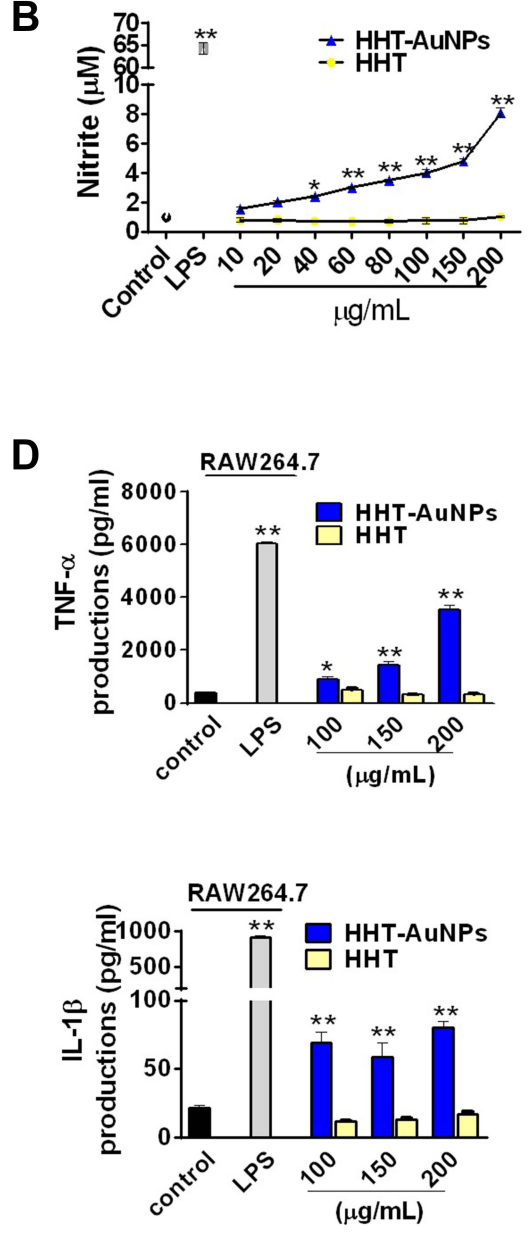

Figure 5 Immunostimulatory activity of HHT-AuNPs on macrophages. (A) Morphological characteristics of RAW264.7 cells after HHT-AuNPs and HHT treatment, the red arrows pointed differentiated RAW264.7 cell; (B) NO production; (C) mRNA expression levels for each targeted cytokine in RAW264.7 cells; (D) TNF- $\alpha$ and IL-I $\beta$ levels in the culture media of RAW264.7 cells. All values are expressed as mean \pm S.D. $* p<0.05, * * p<0.01$ vs control group.

synthesis in macrophages. ${ }^{45}$ Thus, the increased mRNA expression of $i N O S$ explains the enhanced production of $\mathrm{NO}$ (Figure 5B). For the cytokine associated with M2 cell responses, HHT-AuNPs induced the increase of expressions of the IL-10 mRNA by 22.8 -fold, the Arg- 1 mRNA by 8.7-fold, the $I L-4$ mRNA by 5.5-fold, and the $I L-13 \mathrm{mRNA}$ by 7.5 -fold (Figure 5C). In contrast, HHT $(200 \mu \mathrm{g} / \mathrm{mL})$ induced only a slight increase in the expression of $I L-10$ and Arg-1. HHT-AuNPs also induced TNF- $\alpha$ and IL- $1 \beta$ production in RAW 264.7 cells, whereas HHT showed no effect compared to that of the control group (Figure 5D). These observations were confirmed using LPS, a well-known stimulator of macrophages. Our results suggest that the immunostimulatory activity of HHT-AuNPs could lead to the differentiation of macrophages into types M1 and M2. Consistent with our results, previous studies have also reported the immunogenicity of AuNPs. Liu et al confirmed that polyethylene glycosylated AuNPs (PEG@AuNPs) enhanced LPS-induced production of NO and IL-6 and iNOS expression in RAW264.7 cells. $^{39}$ However, PEG@AuNPs themselves did not appear to induce cytokines expression, suggesting that the effect of AuNPs on the macrophage-mediated immune response may depend on the chemistry modifications by different organic polymers after AuNPs synthesis. Hence, the underlying mechanisms of the immunostimulatory activity of HHT-AuNPs require further studies.

\section{HHT-AuNPs Activate MAPKs and NF-KB Signaling Pathways in Macrophages}

In recent years, investigations into the mechanisms of immunostimulatory activity have suggested that regulating intracellular signaling pathways is necessary for the activation of macrophages. ${ }^{1}$ Therefore, to unravel the mechanisms 
underlying the activation of macrophages by HHT-AuNPs, Western blotting was performed to assess their effects on the nuclear transcription factor-kappa $\mathrm{B}(\mathrm{NF}-\mathrm{\kappa B})$ and mitogenactivated protein kinase (MAPK) signaling pathways. MAPK, a serine/threonine-protein kinase, modulates inflammatory mediators and regulates the immune response. ${ }^{46}$ Three representative MAPK signals were confirmed: ERK, JNK, and p38. As shown in Figure 6A, HHT-AuNPs significantly increased the phosphorylation of ERK, JNK, and p38 compared to those observed in untreated cells. Devi et al conjugated nanoparticles with polysaccharides to develop a potential candidate vaccine with immune-enhancing activities, which upregulated the MAPK signaling pathway in RAW264.7 cells. $^{47}$ The activated TLR-MyD88-p38 signaling pathway in RAW264.7 cells can up-regulate phagocytic gene programs and promote phagosome maturation, contributing to macrophage phagocytosis. ${ }^{38}$ Therefore, the HHT-AuNP-triggered MAPK signaling pathway may mediate the immune response and participate in the phagocytosis of AuNPs in macrophages.

$\mathrm{NF}-\kappa \mathrm{B}$, a ubiquitous transcription factor, regulates the expression of multiple cytokines related to host defense. ${ }^{48}$ As shown in Figure 6B, among the tested concentrations, HHT-AuNPs significantly upregulated the expression of phosphorylated $\mathrm{I} \kappa \mathrm{B} \alpha$ and $\mathrm{NF}-\kappa \mathrm{B}$, which was consistent with its effects on mRNA expression and secretion of cytokines as shown in Figure 5C and D. These results strongly indicated that HHT-AuNPs stimulated macrophages by activating both
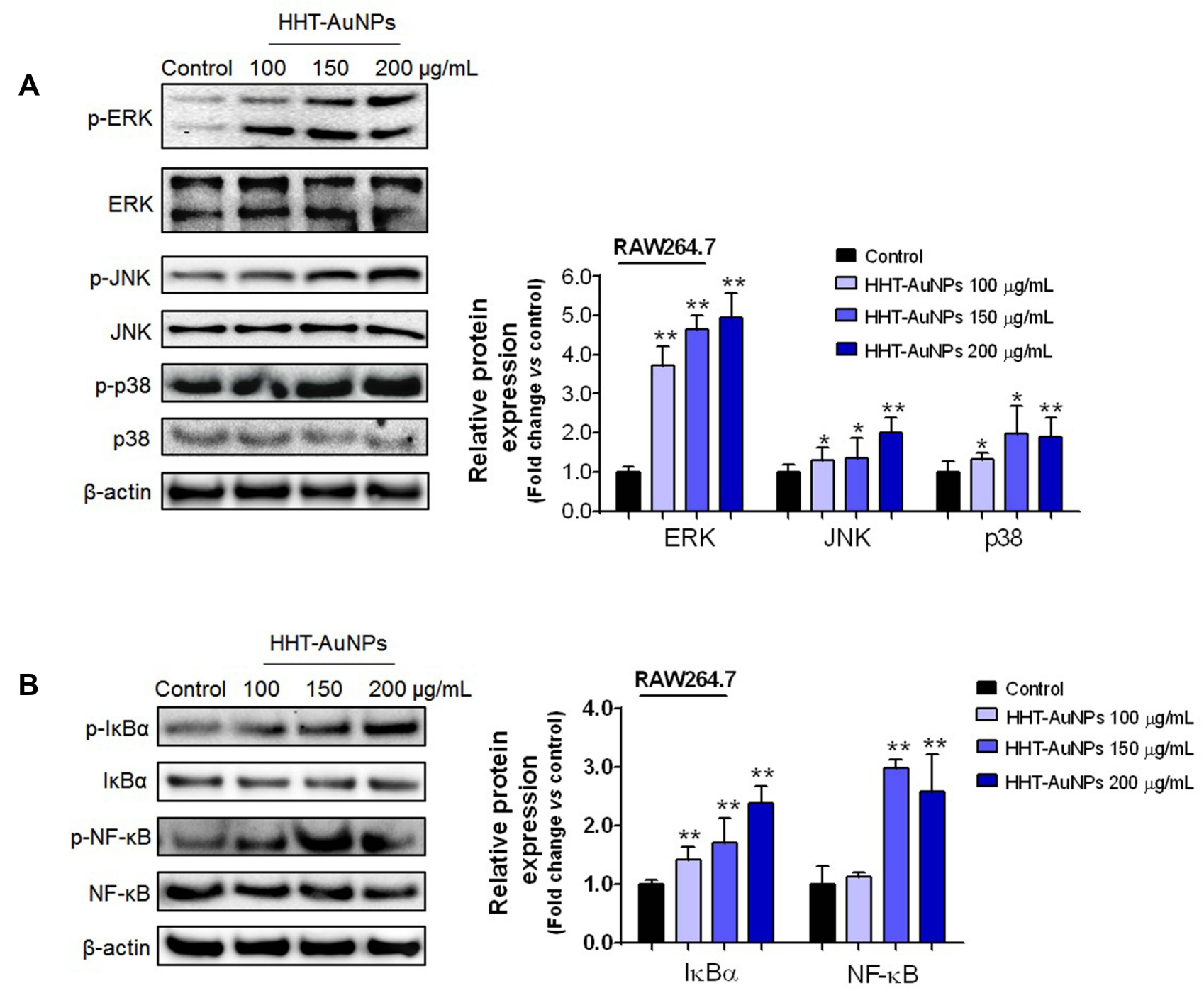

Figure 6 HHT-AuNP-mediated immunostimulation of RAW264.7 cells by activation of the NF- $\mathrm{HB}$ and MAPK signaling pathways. (A) Immunoblotting of ERK, JNK, and p38 proteins in RAW264.7 cells; (B) immunoblotting of $I \kappa B \alpha$ and NF- $\kappa B$ proteins in RAW264.7 cells. All values are expressed as mean \pm S.D. $* p<0.05$, ** $p<0.01$ vs control group. 
the MAPK and NF- $\mathrm{kB}$ signaling pathways. These findings are meaningful for understanding the molecular mechanisms underlying the immunostimulatory effects of AuNPs.

The ex vivo Immunostimulatory Effect of HHT-AuNPs on Mouse Splenocytes

As only a few studies have reported the immunostimulatory effects of biosynthesized AuNPs in splenocytes, we next investigated the immunostimulatory activity of HHTAuNPs using splenocytes ex vivo. As shown in Figure 7A and $\mathrm{B}$, cytotoxicity was not observed at the tested concentrations; rather, the treatment significantly increased cell viability in a dose- and time-dependent manner. Furthermore, HHT-AuNPs significantly increased NO production in splenocytes in a time-dependent manner (Figure 7C), indicating that HHT-AuNPs stimulated macrophages in splenocytes. Splenocytes are composed of various cells (such as T/ B-cells, macrophages, and dendritic cells) with different immune functions and cytokines specific to these immune cells. ${ }^{1}$ TNF- $\alpha$ and IFN- $\gamma$, secreted by Th1 cells, are involved in cell-mediated immune responses, whereas IL-4, IL-6, and IL-10 are Th-2-specific cytokines involved in the humoral immune response. ${ }^{49}$ TNF- $\alpha$ is secreted by T-cells, B-cells, macrophages, and NK cells and inhibits bacterial infections and acute stress to regulate inflammation and host defense. ${ }^{50}$ IL-12 is produced by dendritic cells, macrophages, and B-cells, which promote the production of TNF- $\alpha$ and IFN- $\gamma$ in T-cells and NK cells, respectively. ${ }^{50}$ Concanavalin A (ConA), a widely used mitogen that stimulates T-cell proliferation, can be used as a positive control to investigate the effect of HHT-AuNPs treatment on T-cell activation and production of immune-related cytokines in splenocytes. ${ }^{51}$ As shown in Figure 8A, the effect of HHT-AuNPs on immune cells was evaluated by detecting the mRNA expression and secreted levels of cytokines specific to these immune cells. HHT-AuNPs significantly induced the expression of $T N F-\alpha$, $I L-1 \beta, I L-4, I L-6, I L-10$, and $I L-12$ in splenocytes during 24 $36 \mathrm{~h}$ (Figure 8A). Additionally, IL-2 is a pleiotropic cytokine that promotes T-cell growth, enhances NK cell lytic activity, and induces the differentiation of Treg cells. ${ }^{52}$ Markedly increased expression of IL-2 was observed in splenocytes in response to HHT-AuNPs treatment. IFN- $\gamma$, as a primary immunity-related cytokine, induces the generation of T-cells, activates macrophages and NK cells proliferation, and crossregulates Th1 and Th2 cells. ${ }^{53}$ As shown in Figure 8A, HHTAuNPs induced the expression of IFN- $\gamma$ in splenocytes, which may explain how the HHT-AuNPs induced splenocyte proliferation. Correspondingly, the ELISA results also

B

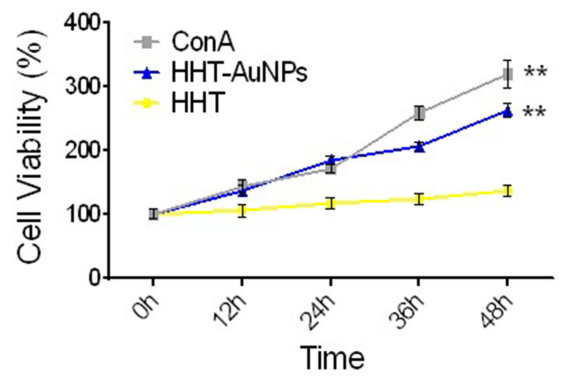

\section{C}

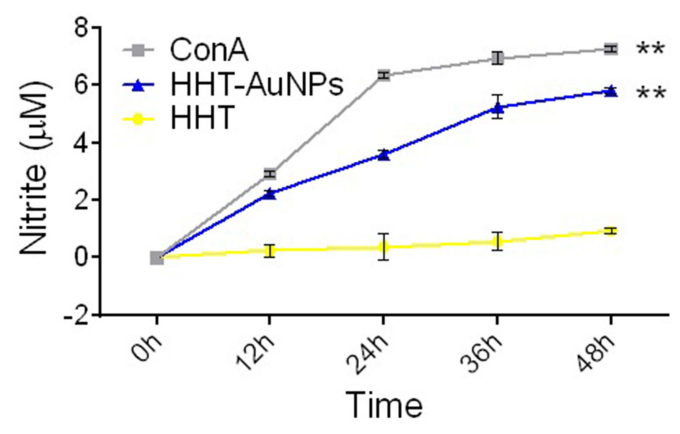

Figure 7 HHT-AuNP-triggered splenocyte proliferation. (A) Effects of increasing concentration of HHT-AuNPs on viability of splenocytes; (B) effects of HHT-AuNPs on cell viability at different times; (C) NO production in splenocytes at different time points. All values are expressed as mean \pm S.D. $* * p<0.0 \mathrm{I}$ vs control group. 
A

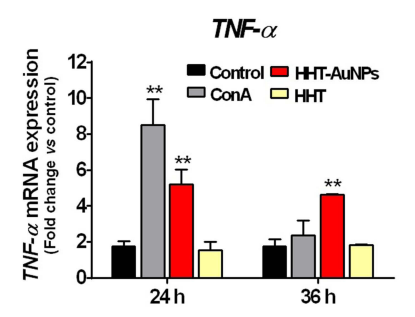

IL-10

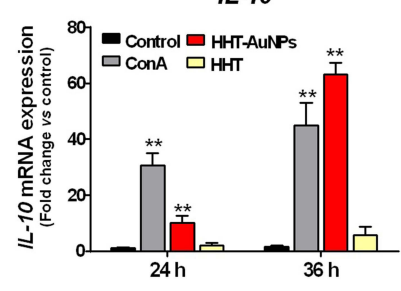

B
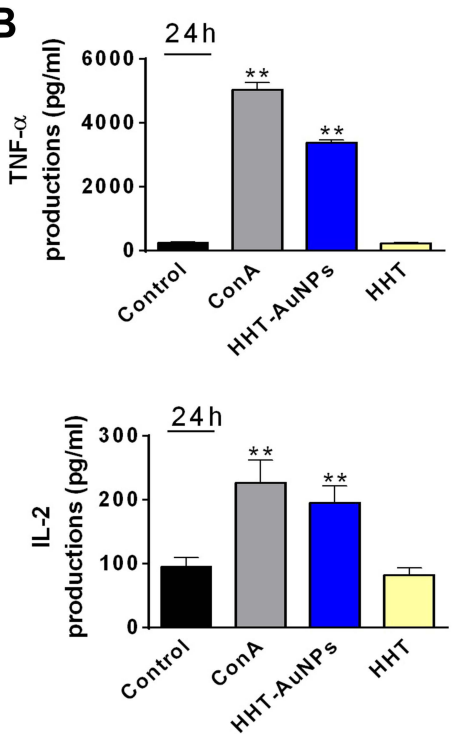

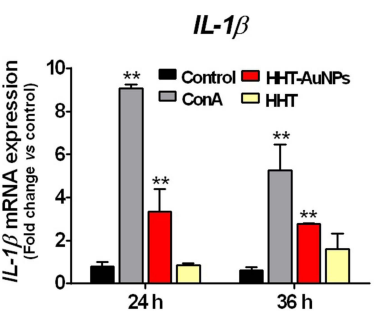

IL-12
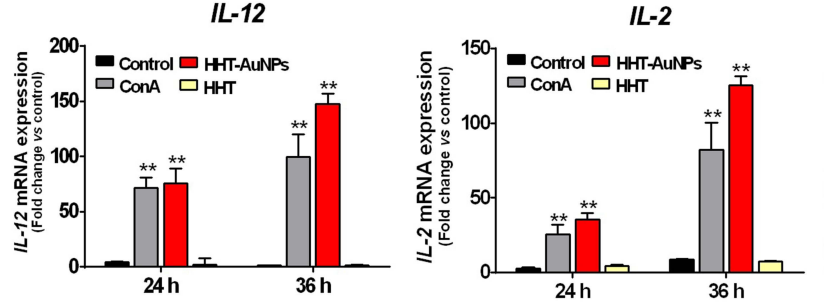

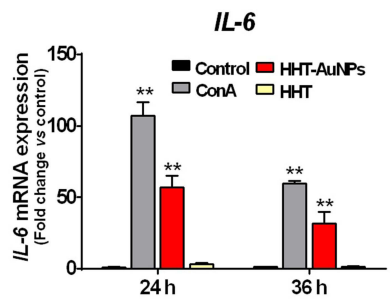

IFN- $\gamma$

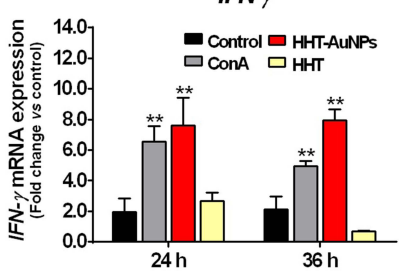

C
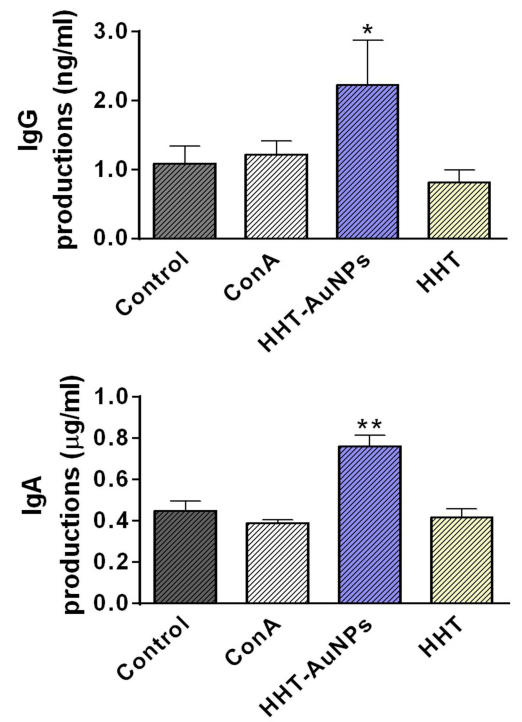

Figure 8 Immunostimulatory effects of HHT-AuNPs on mouse splenocytes. (A) Analysis of mRNA expression levels (TNF- $\alpha$, IL-I $\beta$, IL-4, IL-6, IL-I0, and IL-I2) after HHTAuNPs or HHT treated in splenocytes at different times; (B) TNF- $\alpha$, IL-I $\beta$, IFN- $\gamma$, and IL-2 levels in the culture media of splenocytes. (C) Effect of HHT-AuNPs on immunoglobulin (IgG and $\lg A$ ) levels in splenocytes. All values are expressed as mean \pm S.D. ${ }^{*} p<0.05$, ${ }^{* *} p<0.01$ vs control group.

suggested that HHT-AuNPs significantly increased the production of TNF- $\alpha$, IL-1 $\beta$, IFN- $\gamma$, and IL-2 in splenocytes (Figure 8B). Therefore, the effects of HHT-AuNPs on splenocytes could be viewed as immunostimulatory, whereas HHT did not up-regulate the production of these cytokines. It can be postulated that geniposide, berberine, and baicalin may have undergone chemical modification(s) upon oxidation with $\mathrm{HAuCl}_{4} \cdot 3 \mathrm{H}_{2} \mathrm{O}$, which could have converted them to more active forms. The FTIR results (Figure 3A) also suggested a major modification in organic polymer chemistry after AuNP synthesis. Interestingly, Abdulrahman et al explored the immunomodulatory effects of green synthesized AuNPs from Hypoxis hemerocallidea extract on NK cells, but it inhibited IFN- $\gamma$ production. ${ }^{19}$ Therefore, different plant source-mediated AuNPs can cause contrasting effects on the immune response, which may depend on the chemical modification after AuNPs synthesis using different organic polymers. Modification of the chemistry of organic polymers after AuNP synthesis can only be confirmed by performing more sophisticated spectroscopic analysis of the active compounds and the HHT-AuNPs.

In contrast, stimulated B-cells can be transformed into memory B-cells, and then differentiated into immunoglobulin (Ig, classic immunocompetent molecules), secreting plasma cells to neutralize toxins, bacteria, or viruses, along with regulating immune responses. ${ }^{54} \mathrm{IgG}$ and $\mathrm{IgA}$ are the 
major immunoglobulins involved in the complement activation, and several studies have reported that natural products can enhance the humoral immune response by promoting the production of IgA and IgG. ${ }^{54}$ To understand the mechanism underlying the immune-enhancing activity of HHT-AuNPs, the levels of IgG and IgA in splenocytes were determined using ELISA. As shown in Figure 8C, HHT treatment had no significant effect on the production of IgG or IgA compared with non-treated cells. However, IgG and IgA levels were significantly increased upon HHT-AuNP treatment, suggesting that HHT-AuNPs could improve the immune response by activating B-cells. Collectively, these results confirmed that HHTAuNPs exhibit immunostimulatory effects on mouse splenocytes by priming T-cells and activating macrophages, NK cells, and B-cells.

\section{Conclusion}

In this study, an eco-friendly and efficient biosynthesis method of AuNPs was developed using HHT as the sole agent for both reduction and stabilization. The immunostimulatory activities of HHT-AuNPs were investigated both in vitro and ex vivo. HHT-AuNPs exhibited rapid uptake by macrophages, induced NO production, and upregulated the expression of immune-related cytokines by activating the NF- $\kappa \mathrm{B}$ and MAPK signaling pathways without causing cytotoxicity. The ex vivo studies demonstrated that HHT-AuNPs significantly stimulated splenocyte proliferation and led to NO production. The ex vivo immune-enhancing effect of HHT-AuNPs was also achieved by inducing the expression and production of immune-related cytokines (eg, IL-1 $\beta$, TNF- $\alpha$, IL-4, IL-6, IL-12, IFN- $\gamma$, and IL-2) and biomarkers (IgG and IgA) in splenocytes. Taken together, these results provide strong evidence for the immune-enhancing properties of HHTAuNPs and improve our knowledge about greensynthesized AuNP-mediated immunostimulatory activity (Figure 9). This study may be considered a useful pilot trial in exploring the value of traditional formulae in the nanomedicine field. Various immunostimulants have also been used clinically to treat immunosuppressive diseases, such as cyclophosphamide (CTX)-induced immunosuppression in cancer patients. To explore a more comprehensive potential of these nanoparticles, we shall explore the

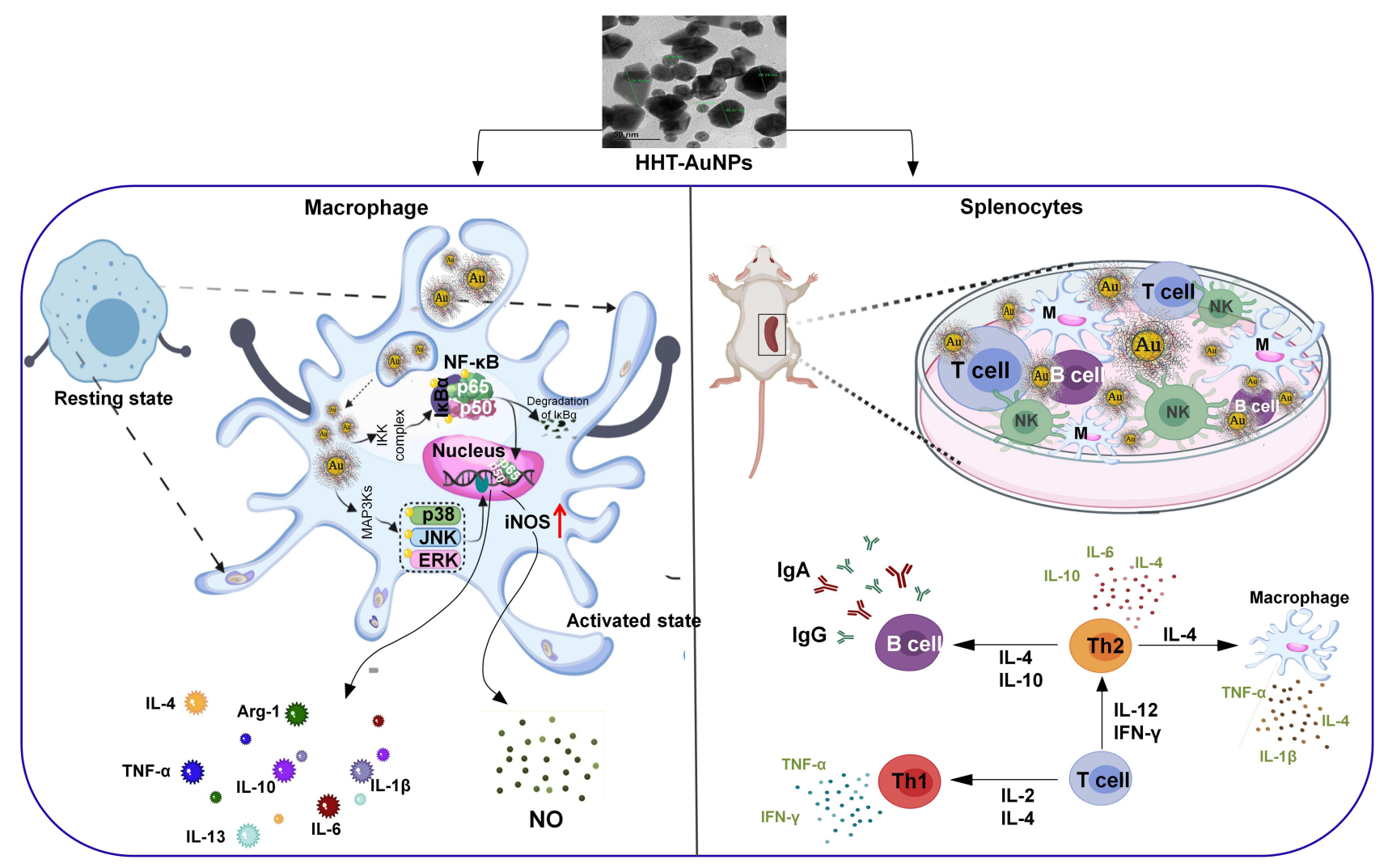

Figure 9 Mechanism of immunoenhancing action of HHT-AuNPs in macrophages and splenocytes. Abbreviations: M, macrophages; T, T lymphocytes; B, B lymphocytes; NK, natural killer cells. 
protective effects of HHT-AuNPs in CTX-treated immunosuppressed mice in future studies.

\section{Acknowledgments}

This work was supported by a grant from the Basic Science Research Program through the National Research Foundation of Korea funded by the Ministry of Education [grant number 2019R1A2C1010428]; the project [grant number 20210491] from Kyung Hee University, Republic of Korea.

\section{Disclosure}

The authors report no conflicts of interest in this work.

\section{References}

1. Hong YH, Yi YS, Han SY, et al. Morinda citrifolia noni water extract enhances innate and adaptive immune responses in healthy mice, ex vivo, and in vitro. Phytother Res. 2019;33:676-689. doi:10.1002/ ptr.6256

2. Ren Z, He C, Fan Y, et al. Immune-enhancing activity of polysaccharides from Cyrtomium macrophyllum. Int $J$ Biol Macromol. 2014;70:590-595. doi:10.1016/j.ijbiomac.2014.07.044

3. Gonzalez H, Robles I, Werb Z. Innate and acquired immune surveillance in the post dissemination phase of metastasis. FEBS $J$ 2018;285:654-664. doi:10.1111/febs.14325

4. Rehman S, Ravinayagam V, Nahvi I, et al. Immunity, sex hormones, and environmental factors as determinants of COVID-19 disparity in women. Front Immunol. 2021;12:680845. doi:10.3389/fimmu.2021.680845

5. Singha S, Shao K, Ellestad KK, et al. Nanoparticles for immune stimulation against infection, cancer, and autoimmunity. ACS Nano. 2018;12:10621-10635. doi:10.1021/acsnano.8b05950

6. Weber JS, Yang JC, Atkins MB, et al. Toxicities of immunotherapy for the practitioner. J Clin Oncol. 2015;33:2092-2099. doi:10.1200/ JCO.2014.60.0379

7. Bahreyni A, Mohamud Y, Luo H. Emerging nanomedicines for effective breast cancer immunotherapy. $J$ Nanobiotechnol. 2020;18:180. doi:10.1186/s12951-020-00741-z

8. Miller G. Nanoparticle treatment reverses cerebral palsy in rabbits. Science. 2012;336:286. doi:10.1126/science.336.6079.286

9. Abdel-Ghany S, Raslan H, Tombuloglu A, et al. Vorinostat-loaded titanium oxide nanoparticles (anatase) induce G2/M cell cycle arres in breast cancer cells via PALB2 upregulation. Biotech. 2020;10:407.

10. Bahadar H, Maqbool F, Niaz K, et al. Toxicity of nanoparticles and an overview of current experimental models. Iran Biomed $J$. 2016;20:1-11. doi:10.7508/ibj.2016.01.001

11. Dykman L, Khlebtsov N. Gold nanoparticles in biomedical applications: recent advances and perspectives. Chem Soc Rev. 2012;41:2256-2282. doi:10.1039/c1cs15166e

12. Nishanthi R, Malathi S, Palani P. Green synthesis and characterization of bioinspired silver, gold and platinum nanoparticles and evaluation of their synergistic antibacterial activity after combining with different classes of antibiotics. Mater Sci Eng C Mater Biol Appl. 2019;96:693-707. doi:10.1016/j.msec.2018.11.050

13. Im AR, Han L, Kim ER, et al. Enhanced antibacterial activities of leonuri herba extracts containing silver nanoparticles. Phytother Res. 2012;26:1249-1255. doi:10.1002/ptr.3683

14. Taqvi S, Ahmed Bhat E, Sajjad N, et al. Protective effect of vanillic acid in hydrogen peroxide-induced oxidative stress in D.Mel-2 cell line. Saudi $J$ Biol Sci. 2021;28:1795-1800. doi:10.1016/j. sjbs.2020.12.023
15. Wei M, Chen N, Li J, et al. Polyvalent immunostimulatory nanoagents with self-assembled $\mathrm{CpG}$ oligonucleotide-conjugated gold nanoparticles. Angew Chem Int Ed Engl. 2012;51:1202-1206. doi:10.1002/anie.201105187

16. Barhate G, Gautam M, Gairola S, et al. Quillaja saponaria extract as mucosal adjuvant with chitosan functionalized gold nanoparticles for mucosal vaccine delivery: stability and immunoefficiency studies. Int J Pharm. 2013;441:636-642. doi:10.1016/j.ijpharm.2012.10.033

17. Barhate G, Gautam M, Gairola S, et al. Enhanced mucosal immune responses against tetanus toxoid using novel delivery system comprised of chitosan-functionalized gold nanoparticles and botanical adjuvant: characterization, immunogenicity, and stability assessment. J Pharm Sci. 2014;103:3448-3456. doi:10.1002/jps.24161

18. Joseph MM, Aravind SR, Varghese S, et al. PST-gold nanoparticle as an effective anticancer agent with immunomodulatory properties. Colloids Surf B Biointerfaces. 2013;104:32-39. doi:10.1016/j. colsurfb.2012.11.046

19. Elbagory AM, Hussein AA, Meyer M. The in vitro immunomodulatory effects of gold nanoparticles synthesized from Hypoxis hemerocallidea aqueous extract and hypoxoside on macrophage and natural killer cells. Int J Nanomed. 2019;14:9007-9018. doi:10.2147/IJN.S216972

20. Du F. The soul outlook in the bamboo slips Fan yin (Anti-excessiveness) of Western Han Dynasty collected at Peking University and in Huang di nei jing (Inner Canon of Yellow Emperor). Zhonghua Yi Shi Za Zhi. 2013;43:259-261.

21. Xiong X, Che CT, Borrelli F, et al. Evidence-based TAM classic herbal formula: from myth to science. Evid Based Complement Alternat Med. 2017;2017:9493076. doi:10.1155/2017/9493076

22. Chi X, Wang S, Baloch Z, et al. Research progress on classical traditional Chinese medicine formula Lily Bulb and Rehmannia Decoction in the treatment of depression. Biomed Pharmacother. 2019;112:108616. doi:10.1016/j.biopha.2019.108616

23. Lu J, Wang JS, Kong LY. Anti-inflammatory effects of Huang-LianJie-Du decoction, its two fractions and four typical compounds. J Ethnopharmacol. 2011;134:911-918. doi:10.1016/j.jep.2011.01.049

24. Zhou X, Peng Y, Li L, et al. Effects of dietary supplementations with the fibrous root of Rhizoma Coptidis and its main alkaloids on non-specific immunity and disease resistance of common carp. Vet Immunol Immunopathol. 2016;173:34-38. doi:10.1016/j.vetimm.2016.03.014

25. Park JI, Shim JK, Do JW, et al. Immune-stimulating properties of polysaccharides from Phellodendri cortex (Hwangbek). Glycoconj J. 1999;16:247-252. doi:10.1023/A:1007084506071

26. An N, Li Y, Huang X, et al. Huanglian Jiedu Decoction for treatment of multiple myeloma: a protocol for a systematic review and meta-analysis. Medicine. 2020;99:e22378. doi:10.1097/ MD.0000000000022378

27. Siddiqi KS, Husen A. Recent advances in plant-mediated engineered gold nanoparticles and their application in biological system. $J$ Trace Elem Med Biol. 2017;40:10-23. doi:10.1016/j.jtemb.2016.11.012

28. Chen G, Fe L, Jin D, et al. Effect of huanglian jiedu decoction on glucose transporter 4 expression in adipose and skeletal muscle tissues of insulin resistant rats. Chin J Integr Med. 2007;13:41-45. doi:10.1007/s11655-007-0041-9

29. Liu Y, Kim S, Kim YJ, et al. Green synthesis of gold nanoparticles using Euphrasia officinalis leaf extract to inhibit lipopolysaccharide-induced inflammation through NF-kappaB and JAK/STAT pathways in RAW 264.7 macrophages. Int J Nanomed. 2019;14:2945-2959. doi:10.2147/IJN.S199781

30. Noh EM, Kim JM, Lee HY, et al. Immuno-enhancement effects of Platycodon grandiflorum extracts in splenocytes and a cyclophosphamide-induced immunosuppressed rat model. BMC Complement Altern Med. 2019;19:322.

31. Elbagory AM, Cupido CN, Meyer M, et al. Large scale screening of southern African plant extracts for the green synthesis of gold nanoparticles using microtitre-plate method. Molecules. 2016;21:1498. doi:10.3390/molecules 21111498 
32. Jimenez Perez ZE, Mathiyalagan R, Markus J, et al. Ginseng-berrymediated gold and silver nanoparticle synthesis and evaluation of their in vitro antioxidant, antimicrobial, and cytotoxicity effects on human dermal fibroblast and murine melanoma skin cell lines. Int J Nanomed. 2017;12:709-723. doi:10.2147/IJN.S118373

33. Abbai R, Mathiyalagan R, Markus J, et al. Green synthesis of multifunctional silver and gold nanoparticles from the oriental herbal adaptogen: Siberian ginseng. Int J Nanomed. 2016;11:3131-3143. doi:10.2147/IJN.S108549

34. Ricci-Junior E, Marchetti JM. Zinc(II) phthalocyanine loaded PLGA nanoparticles for photodynamic therapy use. Int $J$ Pharm. 2006;310:187-195. doi:10.1016/j.ijpharm.2005.10.048

35. Colacio E, Cuesta R, Gutierrez-Zorrilla JM, et al. Gold(I)-purine interactions: synthesis and characterization of cyclic and open chain polynuclear gold(I) complexes containing xanthine derivatives and Bis(phosphine) as bridging ligands. crystal structures of $[\mathrm{Au}(2)$ (\&mgr;-HX)(\&mgr;-dmpe)].3H(2)O and [Au(2)(\&mgr;-TT)(\&mgr;dmpe $). \mathrm{H}(2) \mathrm{O} \quad(\mathrm{H}(3) \mathrm{X}=$ Xanthine; $\mathrm{H}(2) \mathrm{TT}=$ 8-Mercaptotheophylline). Inorg Chem. 1996;35:4232-4238. doi:10.1021/ic951591a

36. Kim J, Lee YM, Kang Y, et al. Tumor-homing, size-tunable clustered nanoparticles for anticancer therapeutics. ACS Nano. 2014;8:9358-9367. doi:10.1021/nn503349g

37. Dykman LA, Khlebtsov NG. Immunological properties of gold nanoparticles. Chem Sci. 2017;8:1719-1735. doi:10.1039/ C6SC03631G

38. Zhang Z, Zhou L, Zhou Y, et al. Mitophagy induced by nanoparticle-peptide conjugates enabling an alternative intracellular trafficking route. Biomaterials. 2015;65:56-65. doi:10.1016/j. biomaterials.2015.06.029

39. Liu Z, Li W, Wang F, et al. Enhancement of lipopolysaccharide-induced nitric oxide and interleukin- 6 production by PEGylated gold nanoparticles in RAW264.7 cells. Nanoscale. 2012;4:7135-7142. doi:10.1039/c2nr31355c

40. Wynn TA, Chawla A, Pollard JW. Macrophage biology in development, homeostasis and disease. Nature. 2013;496:445-455. doi:10.1038/nature 12034

41. Garibaldi S, Barisione C, Marengo B, et al. Advanced oxidation protein products-modified albumin induces differentiation of RAW264.7 macrophages into dendritic-like cells which is modulated by cell surface thiols. Toxins. 2017;9:27. doi:10.3390/toxins9010027

42. Wu F, Zhou C, Zhou D, et al. Immune-enhancing activities of chondroitin sulfate in murine macrophage RAW 264.7 cells. Carbohydr Polym. 2018;198:611-619. doi:10.1016/j. carbpol.2018.06.071
43. Zhang CX, Dai ZR. Immunomodulatory activities on macrophage of a polysaccharide from Sipunculus nudus L. Food Chem Toxicol. 2011;49:2961-2967. doi:10.1016/j.fct.2011.07.044

44. Ji GQ, Chen RQ, Zheng JX. Macrophage activation by polysaccharides from Atractylodes macrocephala Koidz through the nuclear factor-kappaB pathway. Pharm Biol. 2015;53:512-517. doi:10.3109/ 13880209.2014.929152

45. Yunna C, Mengru H, Lei W, et al. Macrophage M1/M2 polarization. Eur J Pharmacol. 2020;877:173090. doi:10.1016/j.ejphar. 2020.173090

46. Juhas U, Ryba-Stanislawowska M, Szargiej P, et al. Different pathways of macrophage activation and polarization. Postepy Hig Med Dosw. 2015;69:496-502. doi:10.5604/17322693.1150133

47. Liu Y, Shepherd EG, Nelin LD. MAPK phosphatases-regulating the immune response. Nat Rev Immunol. 2007;7:202-212. doi:10.1038/ nri2035

48. Devi KS, Sahoo B, Behera B, et al. Nanoparticle and polysaccharide conjugate: a potential candidate vaccine to improve immunological stimuli. Int J Biol Macromol. 2015;72:1254-1264. doi:10.1016/j. ijbiomac.2014.10.026

49. Fang Q, Wang JF, Zha XQ, et al. Immunomodulatory activity on macrophage of a purified polysaccharide extracted from Laminaria japonica. Carbohydr Polym. 2015;134:66-73. doi:10.1016/j. carbpol.2015.07.070

50. Decker T, Muller M, Stockinger S. The yin and yang of type I interferon activity in bacterial infection. Nat Rev Immunol. 2005;5:675-687. doi:10.1038/nri1684

51. Guerra-de-blas PDC, Bobadilla-Del-Valle M, Sada-Ovalle I, et al. Simvastatin enhances the immune response against Mycobacterium tuberculosis. Front Microbiol. 2019;10:2097. doi:10.3389/ fmicb.2019.02097

52. Cadiz MP, Schara MR, Kemp BH, et al. Echinacea purpurea root extract increases tumor necrosis factor production by concanavalin A-activated murine splenocytes. J Med Food. 2019;22:1146-1150. doi:10.1089/jmf.2019.0065

53. Liu N, Dong Z, Zhu X, et al. Characterization and protective effect of Polygonatum sibiricum polysaccharide against cyclophosphamide-induced immunosuppression in Balb/c mice. Int $J$ Biol Macromol. 2018;107:796-802. doi:10.1016/j. ijbiomac.2017.09.051

54. Cai Z, Li W, Wang H, et al. Anti-tumor and immunomodulating activities of a polysaccharide from the root of Sanguisorba officinalis L. Int $J$ Biol Macromol. 2012;51:484-488. doi:10.1016/j. ijbiomac.2012.05.029
International Journal of Nanomedicine

\section{Publish your work in this journal}

The International Journal of Nanomedicine is an international, peerreviewed journal focusing on the application of nanotechnology in diagnostics, therapeutics, and drug delivery systems throughout the biomedical field. This journal is indexed on PubMed Central, MedLine, CAS, SciSearch ${ }^{\mathbb{}}$, Current Contents ${ }^{\mathbb{R}} /$ Clinical Medicine,
Journal Citation Reports/Science Edition, EMBase, Scopus and the Elsevier Bibliographic databases. The manuscript management system is completely online and includes a very quick and fair peer-review system, which is all easy to use. Visit http://www.dovepress.com/ testimonials.php to read real quotes from published authors. 